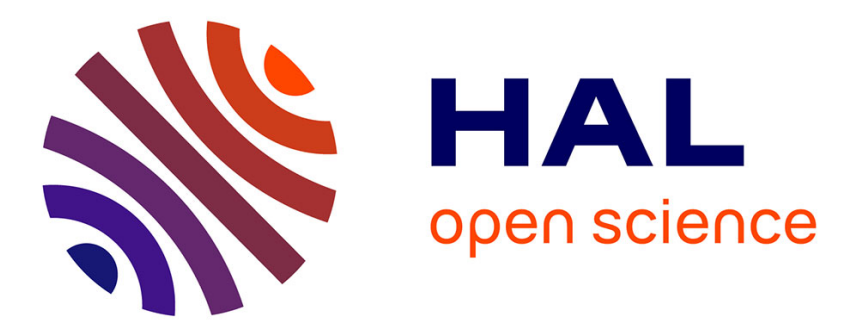

\title{
Laser-assisted vibrational control of precursor molecules in diamond synthesis
}

Yun Shen Zhou, Li Sha Fan, Zhi Qiang Xie, Lan Jiang, Jean-François Silvain, Yong Feng Lu

\section{- To cite this version:}

Yun Shen Zhou, Li Sha Fan, Zhi Qiang Xie, Lan Jiang, Jean-François Silvain, et al.. Laser-assisted vibrational control of precursor molecules in diamond synthesis. Current Opinion in Solid State and Materials Science, 2015, 19 (2), pp.107-144. 10.1016/j.cossms.2014.10.003 . hal-01135944

\author{
HAL Id: hal-01135944 \\ https://hal.science/hal-01135944
}

Submitted on 11 Mar 2021

HAL is a multi-disciplinary open access archive for the deposit and dissemination of scientific research documents, whether they are published or not. The documents may come from teaching and research institutions in France or abroad, or from public or private research centers.
L'archive ouverte pluridisciplinaire HAL, est destinée au dépôt et à la diffusion de documents scientifiques de niveau recherche, publiés ou non, émanant des établissements d'enseignement et de recherche français ou étrangers, des laboratoires publics ou privés. 


\section{Laser-Assisted Vibrational Control of Precursor Molecules in Diamond Synthesis}

Yun Shen Zhou ${ }^{1}$, Li Sha Fan ${ }^{1}$, Zhi Qiang Xie ${ }^{1}$, Lan Jiang ${ }^{2}$, Jean-François Silvain ${ }^{3}$, and Yong Feng Lu ${ }^{*}$

${ }^{1}$ Department of Electrical Engineering, University of Nebraska-Lincoln, Lincoln, NE 68588-0511, USA

${ }^{2}$ School of Mechanical Engineering, Beijing Institute of Technology, Beijing 100081, China

${ }^{3}$ Institut de Chimie de la Matière Condensée de Bordeaux (ICMCB), CNRS, 33608 Pessac, France

*Corresponding Author: Prof. Yong Feng Lu; Department of Electrical Engineering, University of

Nebraska-Lincoln, Lincoln, NE 68588-0511, USA; Email: ylu2@unl.edu; Tel.: 1-402-472-8323; Fax: 1402-472-4732.

Abstract: Control of chemical reactions is the essence of chemistry, producing designed outcomes while suppressing unwanted side products. Laser-assisted molecular vibrational control has been demonstrated to be a potential approach to influencing the outcome of a chemical reaction. In this article, we reviewed recent progress in the laser control of diamond synthesis through vibrational excitation of precursor molecules in a laser-assisted combustion chemical vapor deposition process. Significantly promoted diamond deposition rate $(139 \mu \mathrm{m} / \mathrm{h})$ and crystalline quality were achieved by resonantly exciting the Q-branch $(\Delta \mathrm{J}=0)$ of the $\mathrm{CH}_{2}$-wagging mode $\left(v_{7}\right.$ mode $\left.949.3 \mathrm{~cm}^{-1}\right)$ of $\mathrm{C}_{2} \mathrm{H}_{4}$ molecules. Resonant excitation of the fundamental vibration is more effective in promoting diamond growth than vibrational excitation. Control of diamond crystallographic orientation was also realized by resonantly exciting the $\mathrm{R}$ branch $(\Delta \mathrm{J}=1)$ of the $\mathrm{CH}_{2}$ wagging mode of $\mathrm{C}_{2} \mathrm{H}_{4}$ molecules and resulted in the preferential growth of $\{100\}$-oriented diamond crystals. Nitrogen-doped diamond films with a nitrogen concentration of $1.5 \times 10^{20}$ atoms $/ \mathrm{cm}^{3}$ were synthesized by resonantly exciting the rotational-vibrational transition $(\mathrm{J}=5 \rightarrow \mathrm{J}=6, \mathrm{~K}=0)$ of the $\mathrm{N}-\mathrm{H}$ wagging mode ( $v_{2}$ mode) in ammonia molecules. The findings demonstrate the feasibility of laser-assisted vibration control in steering chemical reactions and controlling reaction outcomes.

Keywords: Diamond; thin film; vibrational excitation; laser; combustion chemical vapor deposition. 


\section{Introduction}

The essence of chemistry is achieving precise control of chemical reactions towards anticipated outcomes while suppressing unwanted side products [1-6]. Conventionally, chemical reactions can be influenced either dynamically, varying external parameters such as temperature, pressure, and concentration, or kinetically, such as utilizing catalysts [1-6]. Since the invention of lasers, laser intervention has been a conceptually appealing tactic to steering chemical reactions and influencing final outcomes. Laser-matter interactions can be either a thermal process or a non-thermal process [1-6]. For a thermal process, incident photons are used primarily as a heating source, in which laser energy is generally deposited into specific reactants and dispersed rapidly to other molecules achieving an equilibrium thermal heating. Similar to conventional thermal driven chemical reactions, the laser thermal process is short of reaction selectivity [1-6]. For a nonthermal process, laser control of chemical reactions can be realized via a number of mechanisms, including 1) controlling molecular vibrational states; 2) photo-isomerization of reactant molecules; 3) exciting electrons to states of different bonding properties; and 4) regulating electron populations at different states [1-6].

Laser-assisted vibrational excitation of molecules is an intuitively attractive approach realizing laser control of chemical reactions [1-6]. In 1972, Polanyi introduced the concept of mode-selective chemistry [7-10], in which vibrational excitation along the reaction coordinate would be more effective than translational motion in promoting endoergic reactions, e.g. the mode of internal excitation could control the reaction outcome. It is expected that the excitation of fundamental vibration or overtone vibration of higher levels would selectively localize energy in a specific bond or a motion along the reaction coordinate, lead to the preferential cleavage of the corresponding bond, and achieve reaction pathway control [7-10]. Extensive investigation on simple molecules, such as HOD [11] (an isotopic variant of water), $\mathrm{HCN}+\mathrm{Cl}$ [12], and $\mathrm{ND}_{3}+\mathrm{NH}_{3}$ [13], has confirmed the validity of the conjecture. Crim reported selective cleavage of chemical bonds and achieving chemical reaction control via vibrational excitation $[2,11,12,14]$, In the reaction of $\mathrm{CH}_{3} \mathrm{D}$ with $\mathrm{Cl}$, excitation of the first overtone of C-D stretch $\left(2 v_{2}\right)$ mode leads to the selective cleavage of the C-D bonds and produces $\mathrm{CH}_{3}$ exclusively [14]. While the excitation of the $\mathrm{C}-\mathrm{H}$ stretch (symmetric $v_{l}$ and antisymmetric $v_{4}$ ) results in the selective cleavage of $\mathrm{C}-\mathrm{H}$ bonds and produce $\mathrm{CH}_{2} \mathrm{D}$ only [14]. Grucebele reported that molecular vibrational energy is of fundamental importance in initiating polyatomic molecule reactions [15]. Keuster revealed that an infrared laser could energize ethylene molecules selectively to highly excited states and differentiate the energy transfer rates from resonant modes to a chemical exit channel [16-18]. However current investigation on the vibrationally controlled chemistry is still limited to small molecules. Extending the labbench concept to more complex reactants and field-scale material synthesis is still a challenge.

Due to its wide range of the most and best properties, diamond has been applied in a wide range of applications. In recent years, we investigated the laser-assisted vibration control of diamond synthesis through vibrational excitation of precursor molecules in a laser-assisted combustion chemical vapor deposition (LACCVD) process [19-23]. Significantly promoted diamond deposition rate $(139 \mu \mathrm{m} / \mathrm{h})$ and crystalline quality were achieved by resonantly exciting the Q-branch $(\Delta \mathrm{J}=0)$ of the $\mathrm{CH}_{2}$-wagging mode (a type $c$ fundamental band, $v_{7}$, at $949.3 \mathrm{~cm}^{-1}$ ) of ethylene $\left(\mathrm{C}_{2} \mathrm{H}_{4}\right)$ molecules [19,20]. Resonant excitation of the fundamental vibration $\left(\mathrm{CH}_{2}-\right.$ wagging mode, $v_{7}$ ) is more effective in laser energy coupling and promoting diamond deposition than vibrational excitation [22]. Control of diamond crystallographic orientation was realized by resonantly exciting the $\mathrm{R}$ branch $(\Delta \mathrm{J}=1)$ of the $\mathrm{CH}_{2}$-wagging mode of $\mathrm{C}_{2} \mathrm{H}_{4}$ molecules and resulted in the preferential growth of $\{100\}$ oriented diamond crystals [23]. Nitrogen-doped diamond films with a nitrogen concentration of 1.5 $\times 10^{20}$ atoms $/ \mathrm{cm}^{3}$ were synthesized by resonantly exciting the rotational-vibrational transition $(\mathrm{J}=5$ $\rightarrow \mathrm{J}^{\prime}=6, \mathrm{~K}=0$ ) of the $\mathrm{N}-\mathrm{H}$ wagging mode ( $v_{2}$ mode) in ammonia molecules [21]. The findings 
demonstrate the feasibility of converting the labbench concept to practical material synthesis.

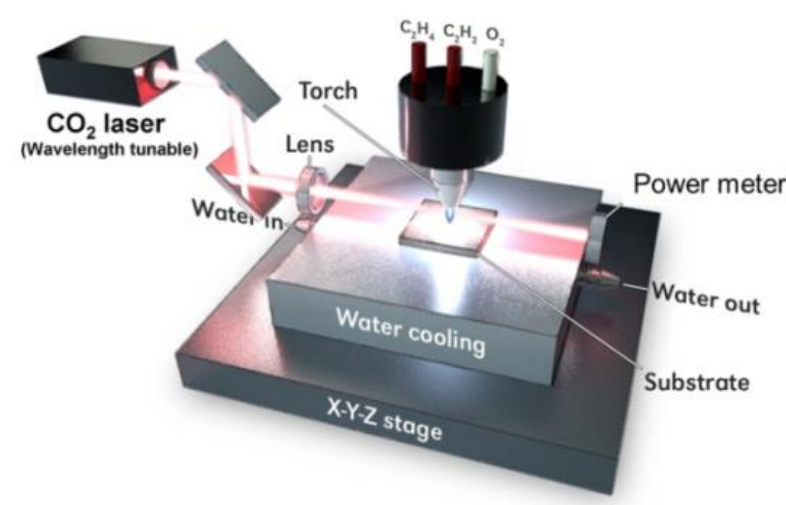

Figure 1. A schematic experimental setup of the LA-CCVD system.

A LA-CCVD system, as shown in Fig. 1, was deployed for growing diamond in open air by using acetylene $\left(\mathrm{C}_{2} \mathrm{H}_{2}\right)$, ethylene $\left(\mathrm{C}_{2} \mathrm{H}_{4}\right)$, and oxygen $\left(\mathrm{O}_{2}\right)$ as precursors. A wavelength tunable $(9.2$ to $10.9 \mu \mathrm{m})$ continuous wave $(\mathrm{CW}) \mathrm{CO}_{2}$ laser was used as the irradiation source to intervene the diamond growth process [19-23].

Based on the first law of photochemistry, the Grotthuss-Draper law, the incident light must be absorbed by a reactant in order to initiate a reaction. Since acetylene does not show obvious absorption peaks within the $\mathrm{CO}_{2}$ laser wavelength range $(9.2$ to $10.9 \mu \mathrm{m})$, ethylene is added into the oxy-acetylene flames due to its obvious absorption bands within the wavelength range, as shown in Fig. 2a. Among several absorption peaks observed, two strongest peaks at 10.532 and $10.22 \mu \mathrm{m}$ are chosen for investigating vibration control of diamond synthesis $[19,20,22,23]$. The strongest absorption peak at $10.532 \mu \mathrm{m}$ is ascribed to the $\mathrm{Q}$ branch $(\Delta \mathrm{J}=0)$ of the $\mathrm{CH}_{2}$-wagging mode (a type $c$ fundamental band, $v_{7}$, at $949.3 \mathrm{~cm}^{-1}$, equivalent to a wavelength of $10.534 \mu \mathrm{m}$ ) of ethylene molecules, as shown in Fig. 2b, involving vibrational excitation only. While the second strongest absorption peak at $10.22 \mu \mathrm{m}$ is attributed to the $\mathrm{R}$ branch $(\Delta \mathrm{J}=1)$ of the $\mathrm{CH}_{2}$-wagging mode of ethylene molecules, as shown in Fig. 2b, involving both vibrational and rotational excitation. Selective excitation of individual vibration controls competition among diamond formation pathways and leads to different outcomes [19,20,22,23].

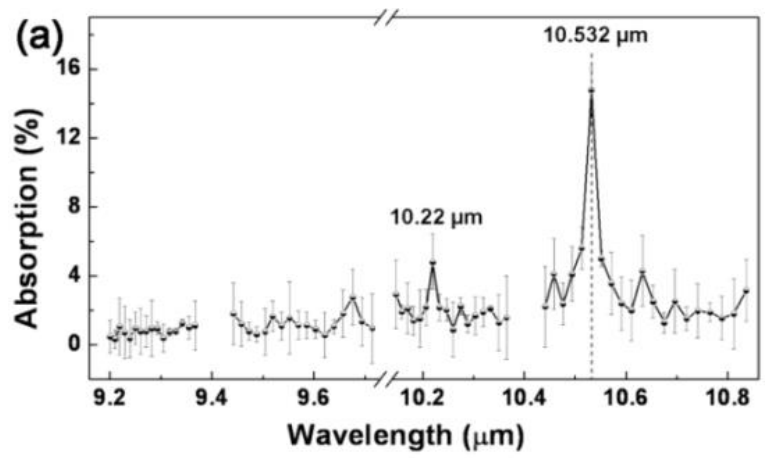

(b)

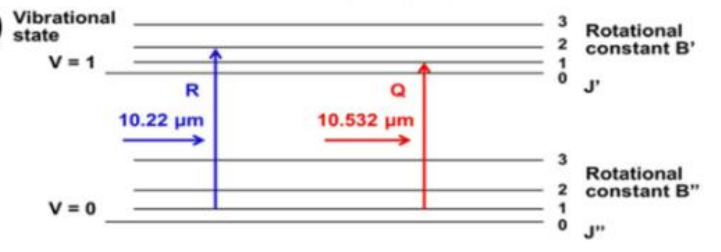

Figure 2. (a) A typical absorption spectrum of the $\mathrm{C}_{2} \mathrm{H}_{2} / \mathrm{C}_{2} \mathrm{H}_{4} / \mathrm{O}_{2}$ flames as a function of laser wavelength from 9.2 to $10.9 \mu \mathrm{m}$. (b) Vibrationrotation transitions of an ethylene molecule at 10.22 and $10.532 \mu \mathrm{m}$, respectively.

\section{Selectively Promoted Diamond Growth by Vibrational Excitation of Ethylene Molecules}

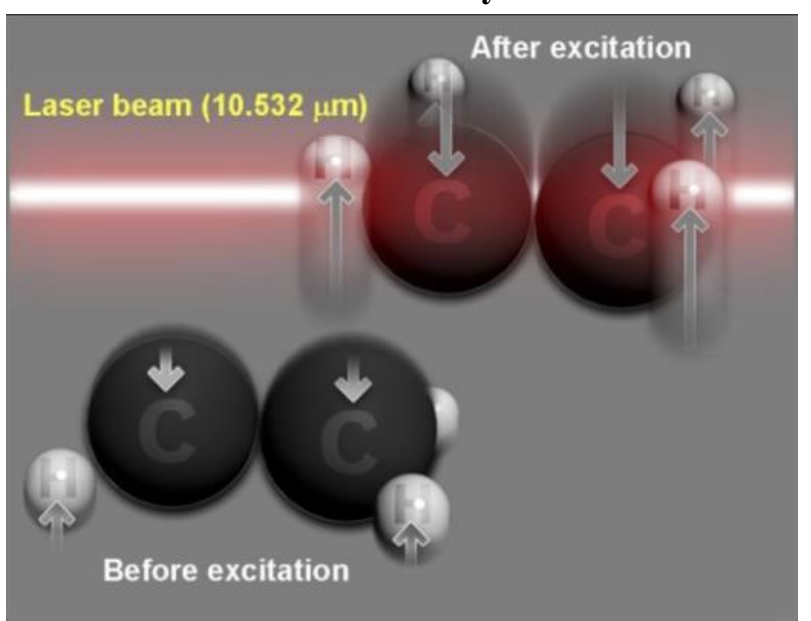

Figure 3. A schematic of the resonantly excited $\mathrm{CH}_{2}$-wagging mode (a type $c$ fundamental mode, $v_{7}$ ) of an ethylene molecule.

Among 12 vibrational modes of ethylene molecules, the butterfly-like $\mathrm{CH}_{2}$-wagging mode $\left(949.3 \mathrm{~cm}^{-1}\right.$ or $\left.10.534 \mu \mathrm{m}\right)$, Fig. 3, demonstrates a 
strong infrared activity and matches closely with the $10.532 \mu \mathrm{m}$ emission line of the $\mathrm{CO}_{2}$ laser. Selective excitation of the $\mathrm{CH}_{2}$-wagging mode could lead to exciting ethylene molecules from the ground state to the first level of excited vibrational state and result in effective energy coupling into the reactants. The influence of the coupled laser energy can be twofold, 1) dispersed as thermal energy and increasing the overall temperature and 2) selectively activating specific species above a particular energy barrier towards corresponding reaction channels. However, it should be pointed out that resonant excitation of the $\mathrm{CH}_{2}$-wagging mode alone cannot lead to the direct bond breaking of the $\mathrm{C}-\mathrm{H}$ bonds in ethylene molecule due to insufficient incident laser power density. Further high-level excitation and dissociation of ethylene molecules are ascribed to the energy pooling effect due to molecular collisions. To verify the influence and selectivity of the vibrational excitation in reaction control, the diamond growth process using acetylene-ethylene-oxygen flames was investigated by tuning laser parameters, including wavelength and output power density.

Due to the wavelength-dependent absorption rate, the wavelength of the incident laser can significantly impact the shape and temperature of the acetylene-ethylene-oxygen flames as shown in Fig. 4 , in which the fundamental $v_{7}$ mode and neighboring vibrational modes are excited. When resonantly exciting the fundamental $v_{7}$ mode at $10.532 \mu \mathrm{m}$, the flame reaches the maximum laser energy absorption rate, highest temperature and shortest flame length, as shown in Fig. 4a to 4c, indicating effective energy coupling and stimulated reactions. The increased flame temperature can stimulate the formation of atomic hydrogen, which helps improving diamond phase purity by etching away non-diamond carbons. The vibrational excitation obviously influences the concentrations of reactive species in the flames, including $\mathrm{C}_{2}, \mathrm{CH}$ and $\mathrm{OH}$, as shown in Fig. $4 \mathrm{~d}$. It is generally accepted that $\mathrm{C}_{2}$ is a beneficiary species stimulating the diamond growth [24],
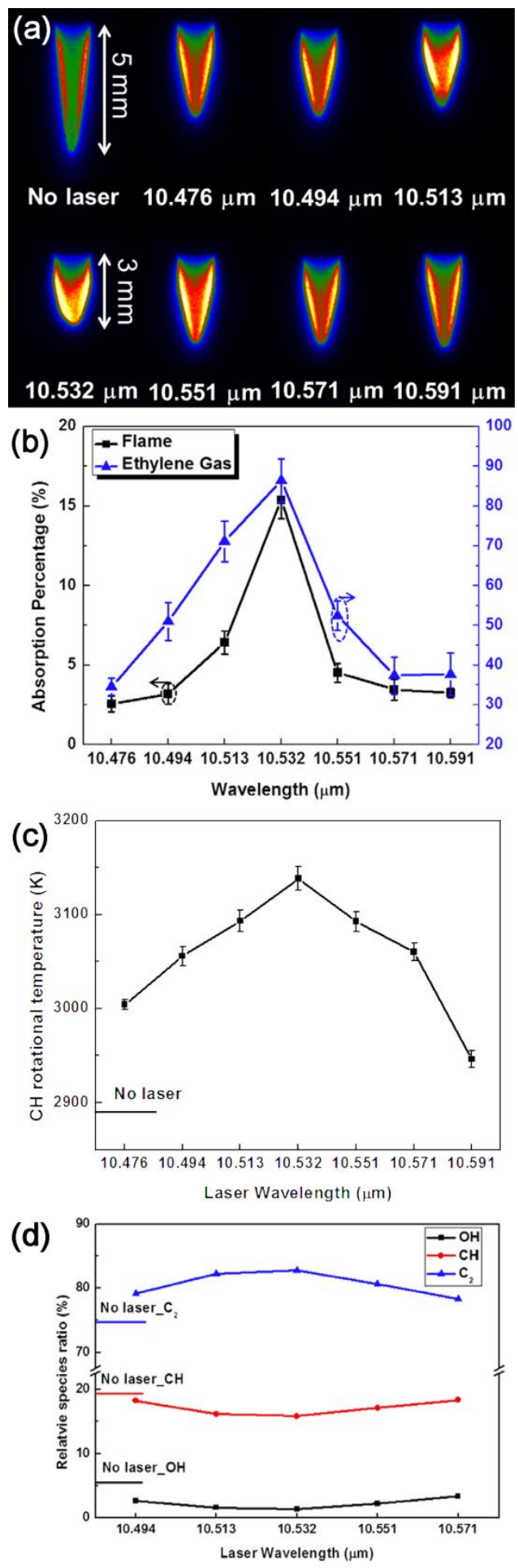

Figure 4. Influence of the laser wavelength: (a) optical images of the acetylene-ethylene-oxygen flames; (b) laser energy absorption rates of the flame (left) and ethylene gas (right); (c) flame temperature; and (d) relative species ratios as the functions of the laser wavelength. 
while $\mathrm{OH}$ is a carbon etchant [25]. The resonant excitation of the fundamental $v_{7}$ mode effectively raises the concentration of $\mathrm{C}_{2}$, suppresses that of $\mathrm{CH}$ and $\mathrm{OH}$, and leads to the selectively promoted diamond growth, as shown in Fig. 5 and 6 . Diamond particle size, crystalline quality, and deposition rate are significantly improved by introducing vibration excitation and reach the highest values when resonantly exciting the $v_{7}$ mode [22].
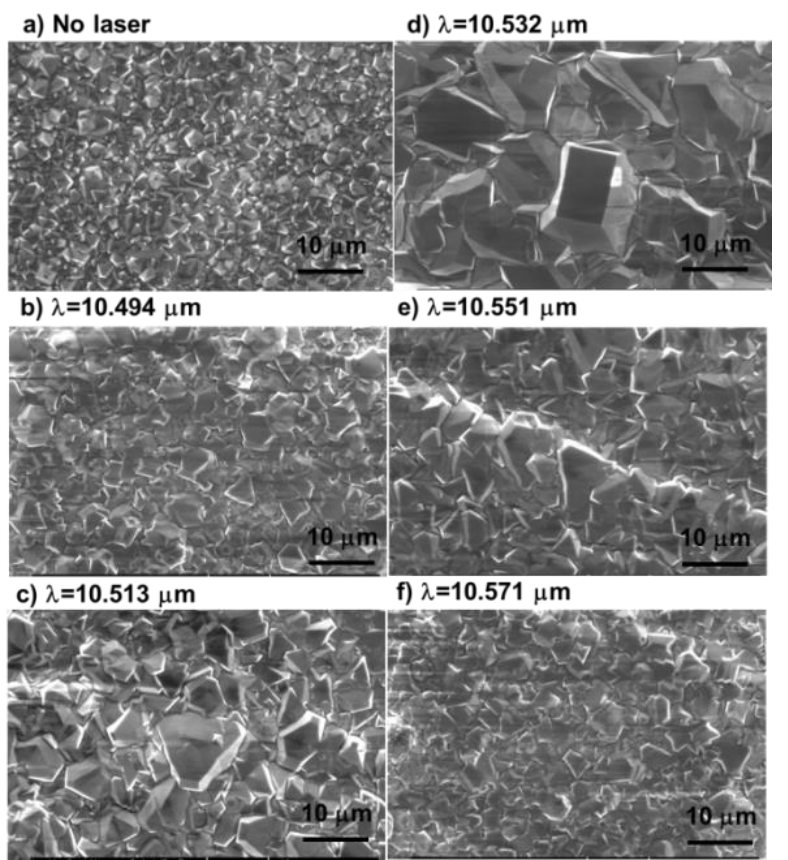

Figure 5. Influence of the laser wavelength: SEM micrographs of diamond films deposited using the LA-CCVD method without laser irradiation and with laser irradiation at different wavelengths.
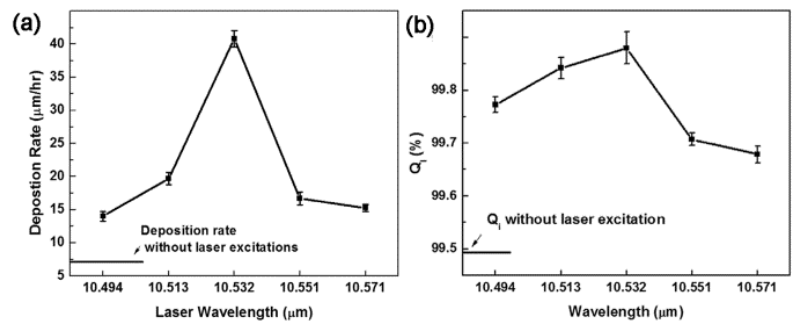

Figure 6. Influence of the laser wavelength: (a) diamond deposition rate and (b) diamond quality factor $(Q)$ as a function of laser wavelength.

Laser power density also plays a critical role in influencing the growth of diamond [19]. As shown in Fig. 7a, the flame length decreases consistently with a broadened width as the laser power density increases, indicating the accelerated reactions. The brightness of the flame also increases continuously as the laser power density rises, representing a higher flame temperature and accelerated reactions. Although the absorbed laser power increases continuously with the rising laser power density, the absorption coefficient decreases due to the saturated laser power absorption. The absorption saturation is ascribed to the anharmonic shift between high-laying vibrational states and decreased absorption cross-sections [26].
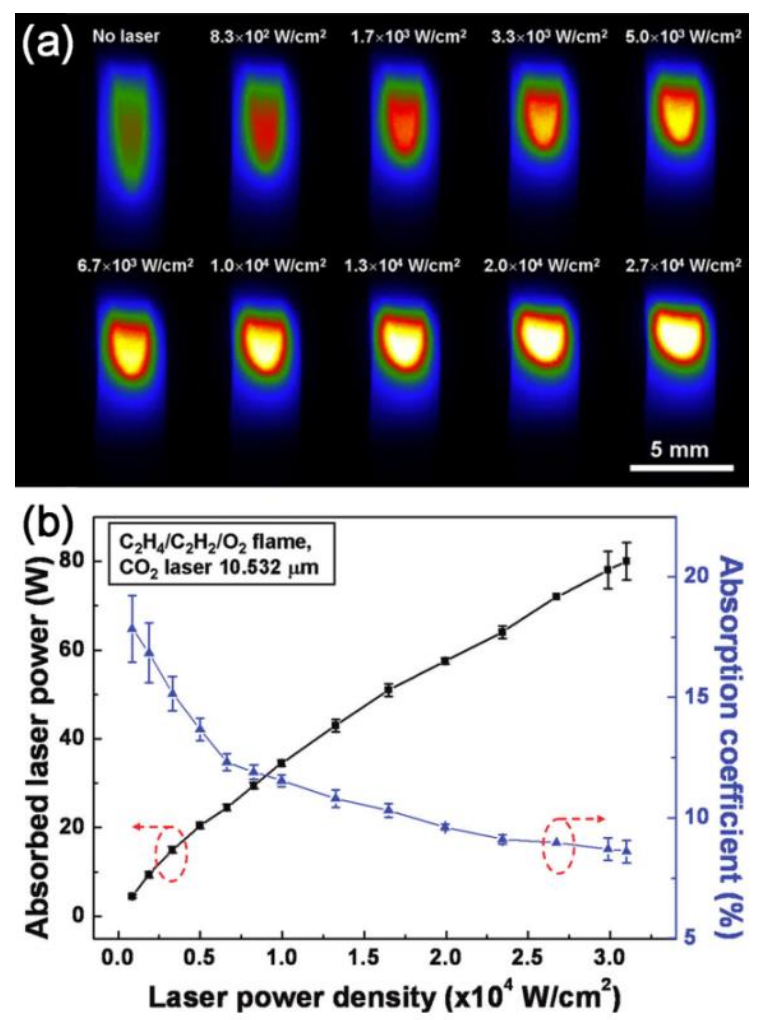

Figure 7. Influence of the laser power density: (a) optical images of the acetylene-ethylene-oxygen flames without laser irradiation and with laser irradiation at different laser power densities, and (b) absorber laser power (left) and absorption coefficient (right) with respect to incident laser power densities, laser wavelength: $10.532 \mu \mathrm{m}$. 
(a) $0.0 \mathrm{~W} / \mathrm{cm}^{2}$

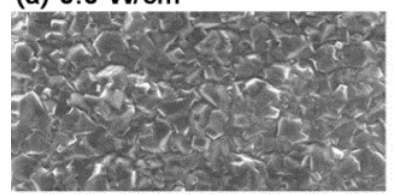

(b) $8.3 \times 10^{2} \mathrm{~W} / \mathrm{cm}^{2}$

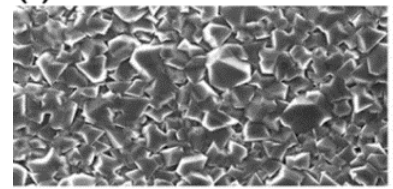

(c) $1.7 \times 10^{3} \mathrm{~W} / \mathrm{cm}^{2}$

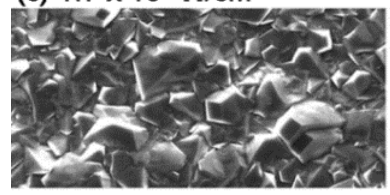

(d) $6.7 \times 10^{3} \mathrm{~W} / \mathrm{cm}^{2}$

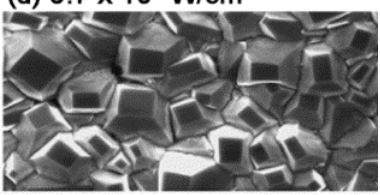

(e) $1.0 \times 10^{4} \mathrm{~W} / \mathrm{cm}^{2}$

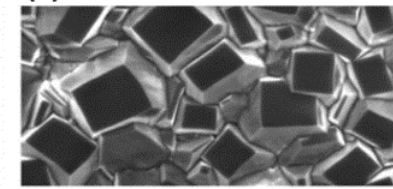

(f) $2.7 \times 10^{4} \mathrm{~W} / \mathrm{cm}^{2}$

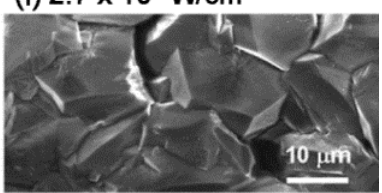

Figure 8. Influence of the laser power density: SEM micrographs diamond films deposited using the LA-CCVD method with laser irradiation at different power densities.

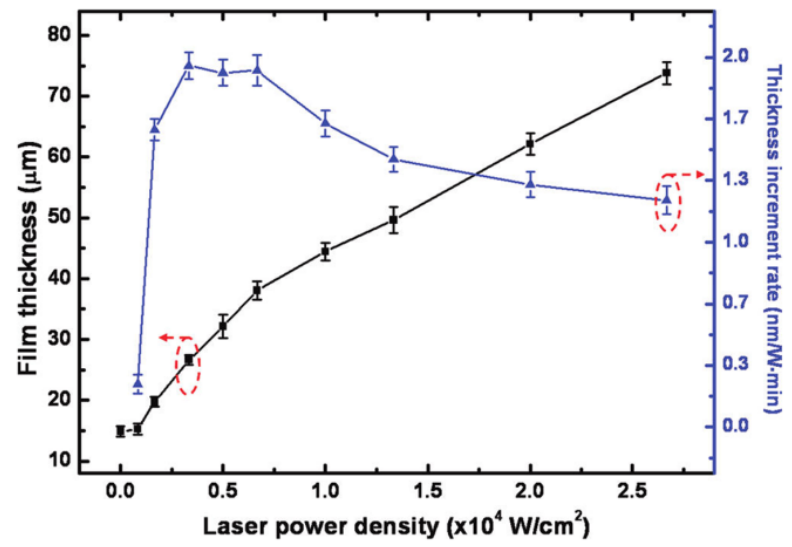

Figure 9. Influence of the laser power density: diamond film thickness (left) and deposition rate (right) as the functions of laser power density.

As the results of the laser power absorption saturation, controlling the incident laser power density can significantly influence the diamond growth in terms of crystalline morphology, grain size, deposition rate, and quality, as shown in Fig. 8 and 9 [19]. When the laser power density increases, diamond grain size increases constantly. Diamond films consisting of dominantly $\{100\}$ oriented diamond crystals are deposited within a narrow power density window, between $5.0 \times 10^{3}$ and $1.0 \times 10^{4} \mathrm{~W} / \mathrm{cm}^{2}$. Otherwise, randomly oriented diamond grains are obtained. The random-(100)- random morphology change is ascribed to the increased $\mathrm{C}_{2}$ concentration in the flames when the laser power density rises. As reported, adding $\mathrm{C}_{2}$ into $\mathrm{C}-\mathrm{H}$ bonds of $\mathrm{H}$-terminated diamond (100) surfaces is energetically favorable on monohydride surfaces $[27,28]$. Therefore, continuous diamond growth can readily start from existing diamond crystals and the (100) facet crystals will dominate. However, when the laser power density surpasses a critical point, $1.0 \times 10^{4} \mathrm{~W} / \mathrm{cm}^{2}$ in our studies, over abundant $\mathrm{C}_{2}$ radicals leads to unhydrided surfaces and results in secondary nucleation from existing crystals, therefore ruining the crystalline orientation selectivity. Although the diamond film thickness increases constantly as the laser power density rises, the thickness increment rate $(\mathrm{nm} / \mathrm{W}$ min) reaches its peak value between $3.3 \times 10^{3}$ and $6.7 \times 10^{3} \mathrm{~W} / \mathrm{cm}^{2}$ and starts to decrease gradually, indicating the saturated absorption, which coincides with the results in Fig. 7. Therefore, the highest laser energy efficiency the best quality diamond are achieved with a power density range between $5.0 \times 10^{3}$ and $6.7 \times 10^{3} \mathrm{~W} / \mathrm{cm}^{2}$.

Therefore, laser wavelength and power density are demonstrated playing critical roles in selectively controlling the diamond growth [19,20,22]. Selectively exciting the $\mathrm{Q}$ branch of the $\mathrm{CH}_{2-}$ wagging mode in ethylene molecules significantly promotes the growth rate and crystalline quality of diamond [19,20,22]. A growth rate of $139 \mu \mathrm{m} / \mathrm{h}$ was achieved with obviously improved $s p^{3}$ carbon phase purity.[20] Resonant vibrational excitation is demonstrated to be more effective than vibrational excitation in coupling incident laser energy and promoting the diamond growth [22]. For a fixed reactant material volume, incident laser power density also shows obvious influence in diamond growth rate and quality [19].

\section{Crystallographic Orientation Control in Diamond Growth}

Energy coupling via vibration excitation influences not only diamond growth rate and crystalline quality but also crystallographic orientation. By intervening different vibrational modes, laser energy is coupled into different channels achieving divergent outcomes. 


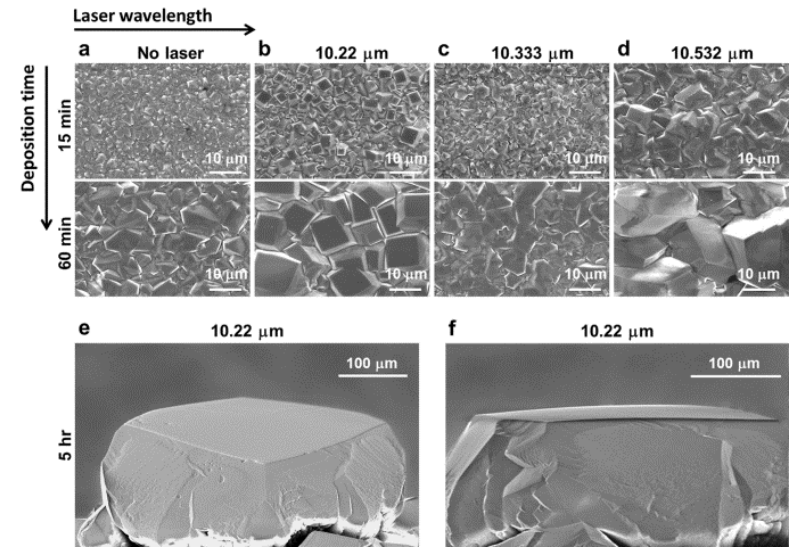

Figure 10. SEM micrographs of the diamond films and particles. (a-d) diamond films deposited without laser (a), with laser irradiation at $10.22 \mu \mathrm{m}$ (b), $10.333 \mu \mathrm{m}$ (c), and 10.532 (d). (e) and (f) single-crystal diamond grown with laser irradiation at $10.22 \mu \mathrm{m}$.

In this study, the $\mathrm{R}$ branch $(\Delta \mathrm{J}=1)$ of the $\mathrm{CH}_{2}-$ wagging mode at $10.22 \mu \mathrm{m}$ was resonantly excited, by which the ethylene molecules are excited to an excited vibrational state level with a higher rotational level, as schematically indicated in Fig. $2 \mathrm{~b}$ [23]. Compared with diamond films deposited under other conditions, $10.22 \mu \mathrm{m}$ irradiation results in the preferential growth of $\{100\}$ textured diamond films, as shown in Fig. 10.
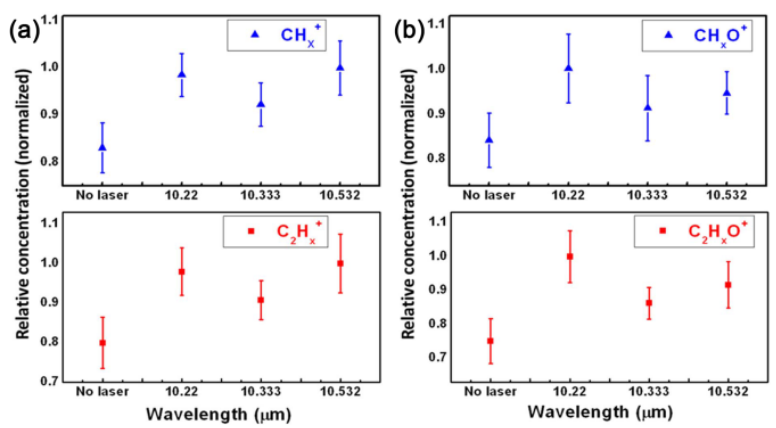

Figure 11. Mass spectrometry of $\mathrm{C}_{2} \mathrm{H}_{2} / \mathrm{C}_{2} \mathrm{H}_{4} / \mathrm{O}_{2}$ flames. Relative concentrations of (a) $\mathrm{C}_{\mathrm{x}} \mathrm{H}_{\mathrm{y}}(\mathrm{x}=1$ and $2, \mathrm{y}=0 \sim 5)$ and (b) $\mathrm{C}_{\mathrm{x}} \mathrm{H}_{\mathrm{y}} \mathrm{O}(\mathrm{x}=1$ and $2, \mathrm{y}=1$ $\sim 5$ ) ions.

According to mass spectrometric studies, the preferential growth of the $\{100\}$ textured diamond films is ascribed to the increased $\mathrm{C}_{\mathrm{x}} \mathrm{H}_{\mathrm{y}} \mathrm{O}$ ions as compared with flames irradiated at other wavelengths, such as $10.532 \mu \mathrm{m}$. As mentioned above, the $10.22 \mu \mathrm{m}$ excitation pump ethylene molecules to a higher vibrational and rotational levels as shown in Fig. 2b. Since the rotationaltranslational translation is much faster than the vibrational-rotational translation for energy transfer, a higher rotational level will result in a more effective translational energy transition, therefore a higher flame temperature [23]. An increased flame temperature leads to a higher concentration of the $\mathrm{C}_{\mathrm{x}} \mathrm{H}_{\mathrm{y}} \mathrm{O}$ ions, which is also verified by Quantum Molecular Dynamics (QMD) simulations. Periodic Density-Functional Theory (DFT) simulations also demonstrate a higher reactivity on $\mathrm{C}\{111\}$ surfaces than $\mathrm{C}\{100\}$ surfaces, therefore a higher growth rate at the $<111>$ direction, resulting in the preferential growth of $\{100\}$ textured diamond films [23].

\section{Synthesis of Nitrogen-Doped Diamond Films}

The same vibrational excitation concept was also extended to other materials, such as nitrogendoped diamond [21].

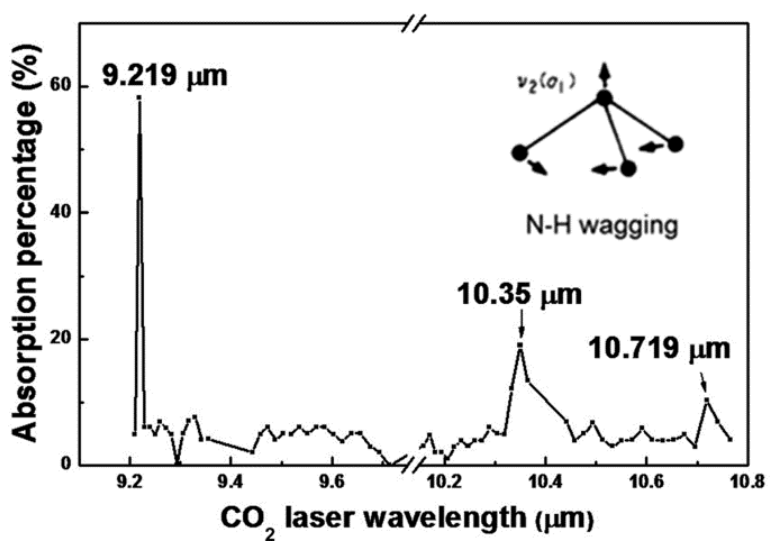

Figure 12. Absorption spectrum of the $\mathrm{CO}_{2}$ laser power by $\mathrm{NH}_{3}$ gas as a function of wavelength.

Doping diamond with nitrogen $(\mathrm{N})$ can improve the electrical conductivity of the diamond [29]. However, a high dose of $\mathrm{N}$ addition easily leads to diamond structure and phase degradation [30]. Therefore, it is desired to realize effective $\mathrm{N}$ addition and still maintain satisfactory crystal quality. In this study, a $\mathrm{NH}_{3}$ added oxy-acetylene flame is used for growing the $\mathrm{N}$-doped diamond. 
Figure 12 shows the absorption spectrum of gaseous $\mathrm{NH}_{3}$ within a spectral range from 9.2 to $10.9 \mu \mathrm{m}$. Three prominent absorption peaks are observed at 9.219, 10.35 and $10.719 \mu \mathrm{m}$. The infrared absorption is ascribed to the $v_{2} \mathrm{~N}-\mathrm{H}$ wagging mode of $\mathrm{NH}_{3}$ molecules, which vibrates in an umbrella inversion mode [31]. Due to the barrier that the $\mathrm{N}$ encounted when traveling through the proton plane, the $v_{2}$ mode is split into two components at $932.51\left(v_{2}+\right)$ and $968.32\left(v_{2^{-}}\right)$ $\mathrm{cm}^{-1}$, respectively [31]. The 9.219 absorption peak arises from the rotational-vibrational transition aat $1084.63 \mathrm{~cm}^{-1}[5(\mathrm{~J})$ to $6(\mathrm{~J} '), \mathrm{K}=0]$ in the $v_{2}$ - band, which perfectly matches the laser line at 1084.71 $\mathrm{cm}^{-1}$ therefore results in a strong laser energy absorption and resonant excitation. Two peaks at 10.35 and $10.719 \mu \mathrm{m}$ are ascribed to the Q-branch at $965.99 \mathrm{~cm}^{-1}[\mathrm{~J}=\mathrm{K}=5]$ in the $v_{2}$ - mode and Qbranch at $932.40 \mathrm{~cm}^{-1}[\mathrm{~J}=\mathrm{K}=2]$ in the $v_{2}+$ mode, respectively [31]. The $0.5 \mathrm{~cm}^{-1}$ mismatch degrades the laser absorption rate at 10.35 and $10.719 \mu \mathrm{m}$.

Figure 13 shows SEM micrographs of the films deposited using the $\mathrm{NH}_{3}$ added oxy-acetylene flame. As expected, cauliflower-like carbon balls consisting of $s p^{2}$ and $s p^{3}$ carbons are obtained without vibration excitaiton, as shown in Fig. 13b and 13c. With vibration excitation, diamond crystals start to appear, Fig. 13d and 13e. When resonantly excited at $9.219 \mu \mathrm{m},(111)$ faceted diamond particles are obtained with a $\mathrm{N}$ doping concentration of $1.5 \times 10^{20}$ atoms $/ \mathrm{cm}^{3}$ [21], which is impossible by using conventional methods. The selective growth of $\mathrm{N}$-doped diamond under vibrational excitation is ascribed to the concentrations of N-containing species in the flames. Vibrational excitation increases the concentrations of $\mathrm{CNO}$ and $\mathrm{H}_{2} \mathrm{CN}$, but supresses the concentratin of $\mathrm{CN}$. The role of $\mathrm{CN}$ can be twofold [32]. At a low concentration, $\mathrm{CN}$ ions derive $\mathrm{H}$ atoms from diamond surface, forming $\mathrm{HCN} / \mathrm{H}_{2} \mathrm{CN}$ and exposing diamond for continous growth. From the other aspect, $\mathrm{CN}$ ions tends to form cyanogen $\left(\mathrm{C}_{2} \mathrm{~N}_{2}\right)$, which leads to the formation of the cauliflower structures [32]. Therefore, selective growth of the $\mathrm{N}$-doped diamond can be achieved by controlling the concentrations of the $\mathrm{N}$-containing species by vibrational exctitation.

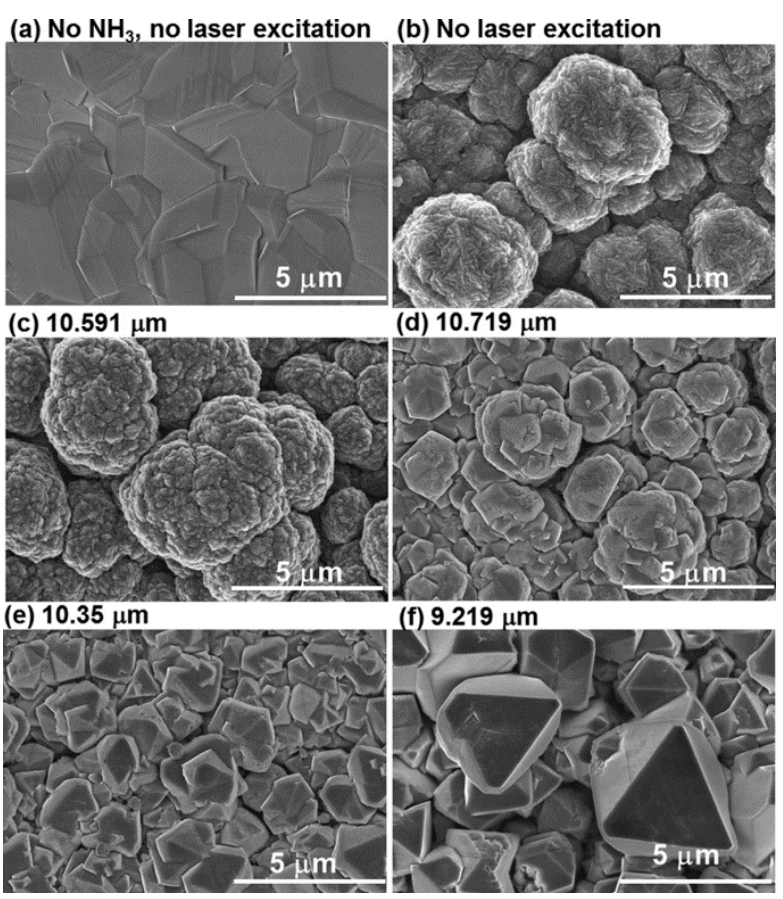

Figure 13. SEM micrographs of diamond films deposited using (a) $\mathrm{NH}_{3}$-free flame without laser excitation, (b) $\mathrm{NH}_{3}$-added flame without laser excitation, and ( $\mathrm{c}-\mathrm{f}) \mathrm{NH}_{3}$-added flame with laser excitation at $10.591,10.719,10.35$ and $9.219 \mu \mathrm{m}$, respectively.

\section{Conclusion}

In conclusion, we investigated laser-assisted vibration control of diamond synthesis. Laser irradiation of matching wavelength was used to intervene the diamond growth process through vibrational excitation of precursor molecules. It is found that vibrational excitation of different states significantly influences the reaction processes and leads to different reaction outcomes. Selectively exciting the Q-branch $(\Delta \mathrm{J}=0)$ of the $\mathrm{CH}_{2}$-wagging mode of $\mathrm{C}_{2} \mathrm{H}_{4}$ molecules results in significantly promoted diamond deposition rate $(139 \mu \mathrm{m} / \mathrm{h})$ and crystalline quality. Resonant excitation of the fundamental vibration $\left(\mathrm{CH}_{2}\right.$-wagging mode, $\left.v_{7}\right)$ is more effective in laser energy coupling and promoting diamond deposition than vibrational excitation. Preferential growth of $\{100\}$-oriented diamond crystals is achieved by resonantly exciting the $\mathrm{R}$ branch $(\Delta \mathrm{J}=1)$ of the $\mathrm{CH}_{2}$-wagging mode of $\mathrm{C}_{2} \mathrm{H}_{4}$ molecules. Resonant excitation of the $\mathrm{N}-\mathrm{H}$ wagging mode $\left(v_{2}\right.$ mode) in $\mathrm{NH}_{3}$ 
molecules effectively increases nitrogen concentration in Nitrogen-doped diamond. The results demonstrate the feasibility of laser-assisted vibration control of material synthesis for controllable and selective material synthesis.

\section{Acknowledgement}

The research work was financially supported by the U.S. Office of Naval Research (N00014-05-10432, N00014-09-1-0943, and N00014-09-75810943) and National Science Foundation (CMMI 1129613 and 1068510). The authors are grateful to Dr. I. Perez from the U.S. Office of Naval Research for his invaluable scientific advice and support. 


\section{References}

1. Brumer P, Shapiro M: Laser control of chemical-reactions. Sci Am (1995) 272(3):56\&.

2. Crim FF: Chemical dynamics of vibrationally excited molecules: Controlling reactions in gases and on surfaces. P Natl Acad Sci USA (2008) 105(35):12654-12661.

3. Henriksen NE: Laser control of chemical reactions. Chem Soc Rev (2002) 31(1):37-42.

4. Quack M, Engel V, Manz J, Shapiro M, Woste L, Korolkov MV, Paramonov GK, Kellman ME, Child MS, Kobayashi T, Jain SR et al: General discussion on laser control of chemical reactions. Adv Chem Phys (1997) 101:373-388.

5. Torralva BR, Allen RE: Mechanisms for laser control of chemical reactions. J Mod Optic (2002) 49(3-4):593-625.

6. Zare RN: Laser control of chemical reactions. Science (1998) 279(5358):1875-1879.

7. Polanyi JC: Some concepts in reaction dynamics. Accounts Chem Res (1972) 5(5):161-\&.

8. Polanyi JC: Some concepts in reaction dynamics - (nobel lecture). Angew Chem Int Edit (1987) 26(10):952-971.

9. Polanyi JC: Some concepts in reaction dynamics. Chem Scripta (1987) 27(2):229-247.

10. Polanyi JC: Some concepts in reaction dynamics. Science (1987) 236(4802):680-690.

11.Metz RB, Thoemke JD, Pfeiffer JM, Crim FF: Selectively breaking either bond in the bimolecular reaction of hod with hydrogenatoms. J Chem Phys (1993) 99(3):1744-1751.

12. Metz RB, Pfeiffer JM, Thoemke JD, Crim FF: The reaction of chlorine atoms with highly vibrationally excited hon. Chem Phys Lett (1994) 221(5-6):347-352.

13. Guettler RD, Jones GC, Posey LA, Zare RN: Partial control of an ion-molecule reaction by selection of the internal motion of the polyatomic reagent ion. Science (1994) 266(5183):259-261.

14. Yoon S, Holiday RJ, Crim FF: Vibrationally controlled chemistry: Mode- and bond-selected reaction of ch3d with ci. J Phys Chem B (2005) 109(17):8388-8392.

15. Gruebele M, Wolynes PG: Vibrational energy flow and chemical reactions. Accounts Chem Res (2004) 37(4):261-267.
16. Dekeuster D, Hemptinne XD: Physical and chemical relaxations in ethylene following co2laser irradiation - time of flight observations. B Soc Chim Belg (1979) 88(1-2):1-12.

17. Dekeuster D, Hemptinne XD: Chemical relaxation in cw co2-laser irradiated ethylene at low-pressure. J Chem Phys (1979) 70(11):53195321.

18. Hemptinne XD: Contribution to photochemistry, ethylene laser. J Chim Phys Pcb (1979) 76(7-8):731-731.

19. Xe ZQ, He XN, Hu W, Guillemet T, Park JB, Zhou YS, Bai J, Gao Y, Zeng XC, Jiang L, Lu YF: Excitations of precursor molecules by different laser powers in laser-assisted growth of diamond films. Cryst Growth Des (2010) 10(11):4928-4933.

20. Xie ZQ, Zhou YS, He XN, Gao Y, Park J, Ling H, Jiang L, Lu YF: Fast growth of diamond crystals in open air by combustion synthesis with resonant laser energy coupling. Cryst Growth Des (2010) 10(4):1762-1766.

21. Fan LS, Xie ZQ, Park JB, He XN, Zhou YS, Jiang L, Lu YF: Synthesis of nitrogen-doped diamond films using vibrational excitation of ammonia molecules in laser-assisted combustion flames. J Laser Appl (2012) 24(2):022001.

22. Fan LS, Zhou YS, Wang MX, Gao Y, Liu L, F. SJ, Lu YF: Resonant vibrational excitation of ethylene molecules in laser-assisted diamond deposition. Laser Physics Letters (2014) 11:076002.

23. Xie ZQ, Bai J, Zhou YS, Gao Y, Park J, Guillemet T, Jiang L, Zeng XC, Lu YF: Control of crystallographic orientation in diamond synthesis through laser resonant vibrational excitation of precursor molecules. Sci Rep-Uk (2014) 4:4581.

24. Matsui Y, Yuuki A, Sahara M, Hirose Y: Flame structure and diamond growthmechanism of acetylene torch. Jpn J Appl Phys 1 (1989) 28(9):1718-1724.

25. Komaki K, Yanagisawa M, Yamamoto I, Hirose Y: Synthesis of diamond in combustion flame under low-pressures. Jpn J Appl Phys 1 (1993) 32(4):1814-1817.

26. Yao L, Mebel AM, Lu HF, Neusser HJ, Lin SH: Anharmonic effect on unimolecular 
reactions with application to the photodissociation of ethylene. J Phys Chem A (2007) 111(29):6722-6729.

27. Gruen DM, Redfern PC, Horner DA, Zapol P, Curtiss LA: Theoretical studies on nanocrystalline diamond: Nucleation by dicarbon and electronic structure of planar defects. J Phys Chem B (1999) 103(26):54595467.

28. Redfern PC, Horner DA, Curtiss LA, Gruen DM: Theoretical studies of growth of diamond (110) from dicarbon. J Phys Chem-Us (1996) 100(28):11654-11663.

29. Okano K, Koizumi S, Silva SRP, Amaratunga GAJ: Low-threshold cold cathodes made of nitrogen-doped chemical-vapour-deposited diamond. Nature (1996) 381(6578):140-141.

30. Atakan B, Beuger M, Kohse-Hoinghaus K: Nitrogen compounds and their influence on diamond deposition in flames. Phys Chem Chem Phys (1999) 1(4):705-708.

31. David CW: Ir vibration-rotation spectra of the ammonia molecule. J Chem Educ (1996) 73(1):46-50.

32. Hong TM, Chen SH, Chiou YS, Chen CF: Optical-emission spectroscopy studies of the effects of nitrogen addition on diamond synthesis in a ch4-co2 gas-mixture. Appl Phys Lett (1995) 67(15):2149-2151. 


\section{Figure captions}

Figure 1. A schematic experimental setup of the LA-CCVD system.

Figure 2. (a) A typical absorption spectrum of the $\mathrm{C}_{2} \mathrm{H}_{2} / \mathrm{C}_{2} \mathrm{H}_{4} / \mathrm{O}_{2}$ flames as a function of laser wavelength from 9.2 to $10.9 \mu \mathrm{m}$. (b) Vibration-rotation transitions of an ethylene molecule at 10.22 and $10.532 \mu \mathrm{m}$, respectively.

Figure 3. A schematic of the resonantly excited $\mathrm{CH}_{2}$-wagging mode (a type $c$ fundamental mode, $v_{7}$ ) of an ethylene molecule.

Figure 4. Influence of the laser wavelength: (a) optical images of the acetylene-ethylene-oxygen flames; (b) laser energy absorption rates of the flame (left) and ethylene gas (right); (c) flame temperature; and (d) relative species ratios as the functions of the laser wavelength.

Figure 5. Influence of the laser wavelength: SEM micrographs of diamond films deposited using the LACCVD method without laser irradiation and with laser irradiation at different wavelengths.

Figure 6. Influence of the laser wavelength: (a) diamond deposition rate and (b) diamond quality factor $(Q)$ as a function of laser wavelength.

Figure 7. Influence of the laser power density: (a) optical images of the acetylene-ethylene-oxygen flames without laser irradiation and with laser irradiation at different laser power densities, and (b) absorber laser power (left) and absorption coefficient (right) with respect to incident laser power densities, laser wavelength: $10.532 \mu \mathrm{m}$.

Figure 8. Influence of the laser power density: SEM micrographs diamond films deposited using the LACCVD method with laser irradiation at different power densities. 
Figure 9. Influence of the laser power density: diamond film thickness (left) and deposition rate (right) as the functions of laser power density.

Figure 10. SEM micrographs of the diamond films and particles. (a-d) diamond films deposited without laser (a), with laser irradiation at $10.22 \mu \mathrm{m}$ (b), $10.333 \mu \mathrm{m}$ (c), and 10.532 (d). (e) and (f) singlecrystal diamond grown with laser irradiation at $10.22 \mu \mathrm{m}$.

Figure 11. Mass spectrometry of $\mathrm{C}_{2} \mathrm{H}_{2} / \mathrm{C}_{2} \mathrm{H}_{4} / \mathrm{O}_{2}$ flames. Relative concentrations of (a) $\mathrm{C}_{\mathrm{x}} \mathrm{H}_{\mathrm{y}}(\mathrm{x}=1$ and $2, \mathrm{y}$ $=0 \sim 5)$ and (b) $\mathrm{C}_{\mathrm{x}} \mathrm{H}_{\mathrm{y}} \mathrm{O}(\mathrm{x}=1$ and $2, \mathrm{y}=1 \sim 5)$ ions.

Figure 12. Absorption spectrum of the $\mathrm{CO}_{2}$ laser power by $\mathrm{NH}_{3}$ gas as a function of wavelength.

Figure 13. SEM micrographs of diamond films deposited using (a) $\mathrm{NH}_{3}$-free flame without laser excitation, (b) $\mathrm{NH}_{3}$-added flame without laser excitation, and (c - f) $\mathrm{NH}_{3}$-added flame with laser excitation at $10.591,10.719,10.35$ and $9.219 \mu \mathrm{m}$, respectively. 


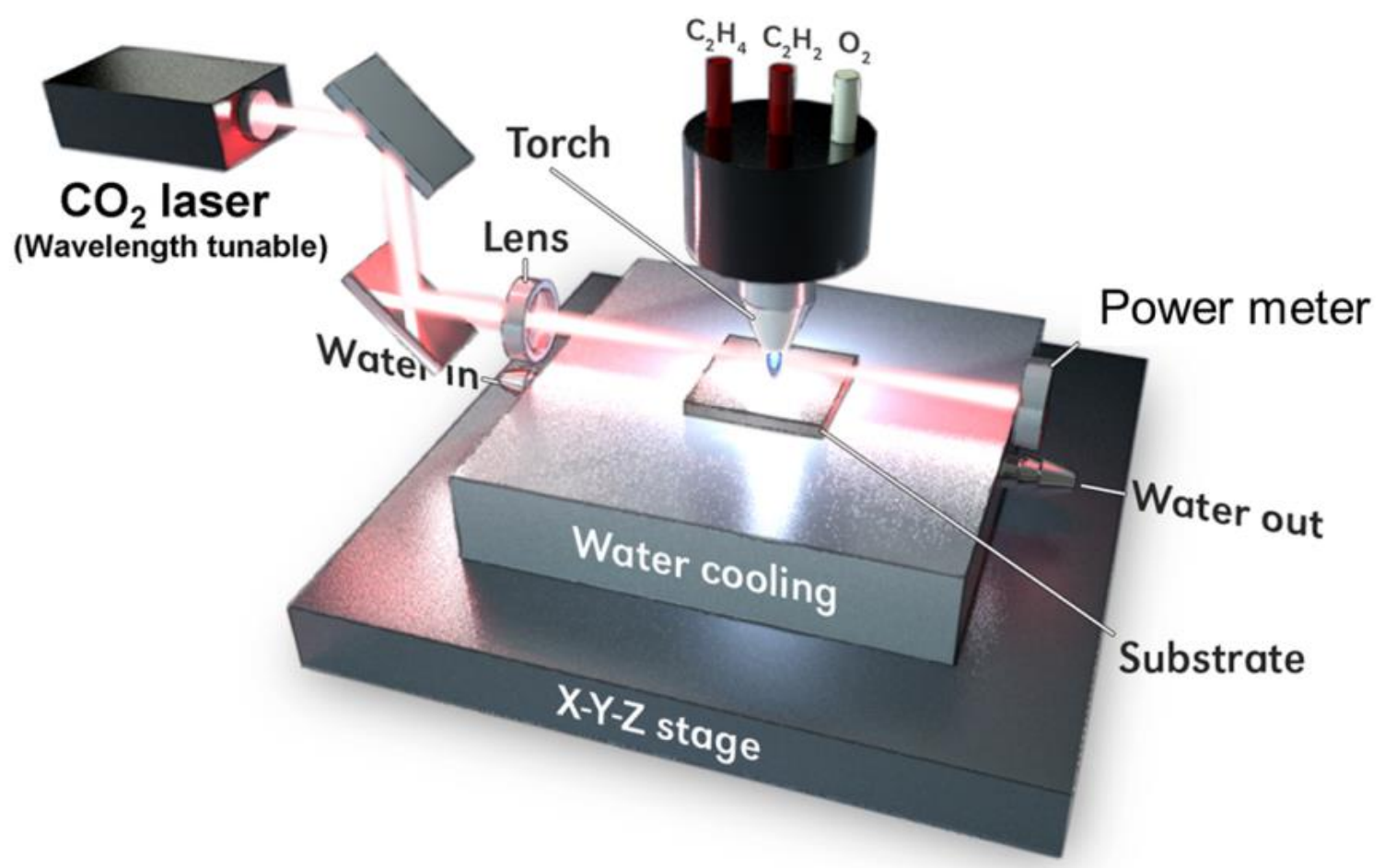

Figure 1 

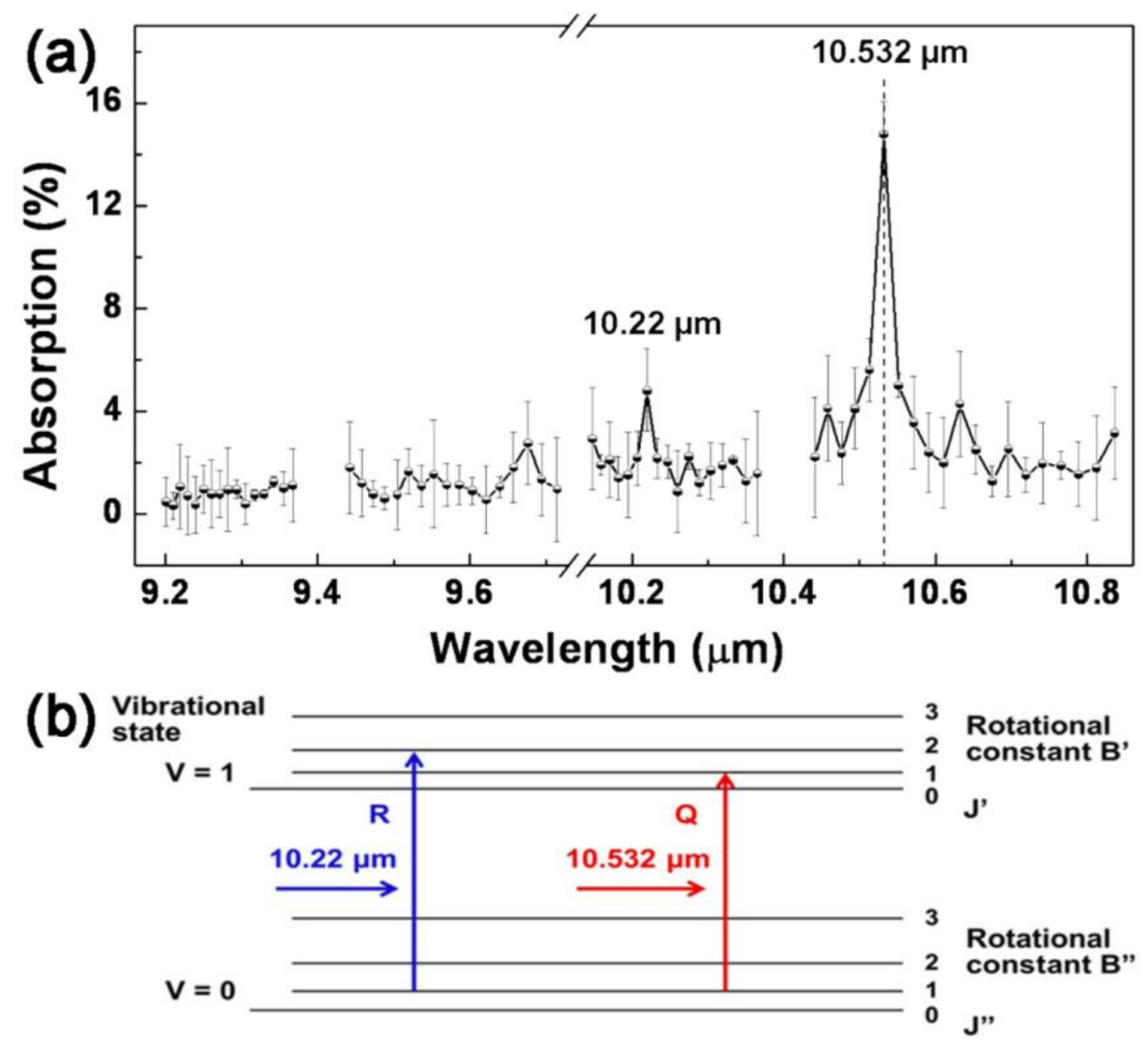

Figure 2 


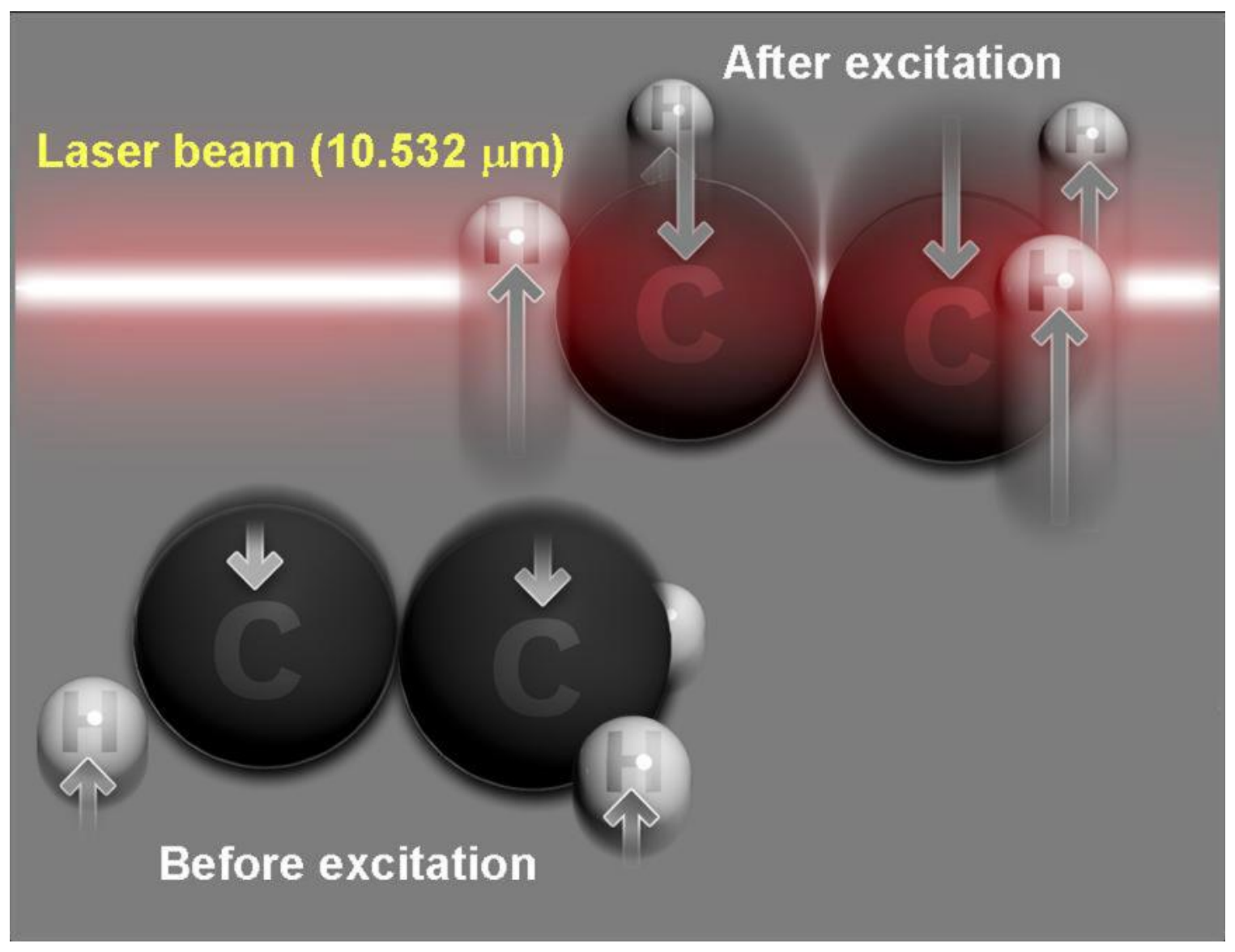

Figure 3 


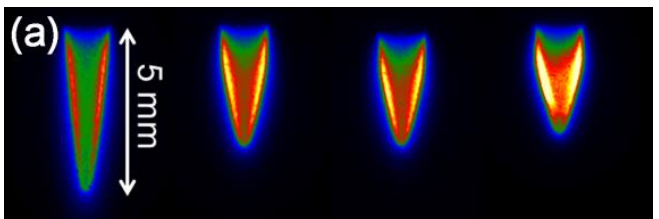

No laser $10.476 \mu \mathrm{m} 10.494 \mu \mathrm{m} 10.513 \mu \mathrm{m}$

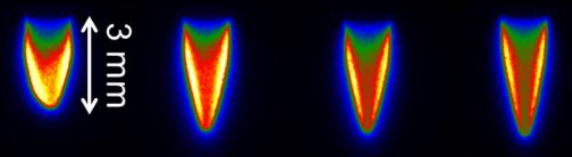

$10.532 \mu \mathrm{m} 10.551 \mu \mathrm{m} 10.571 \mu \mathrm{m} 10.591 \mu \mathrm{m}$
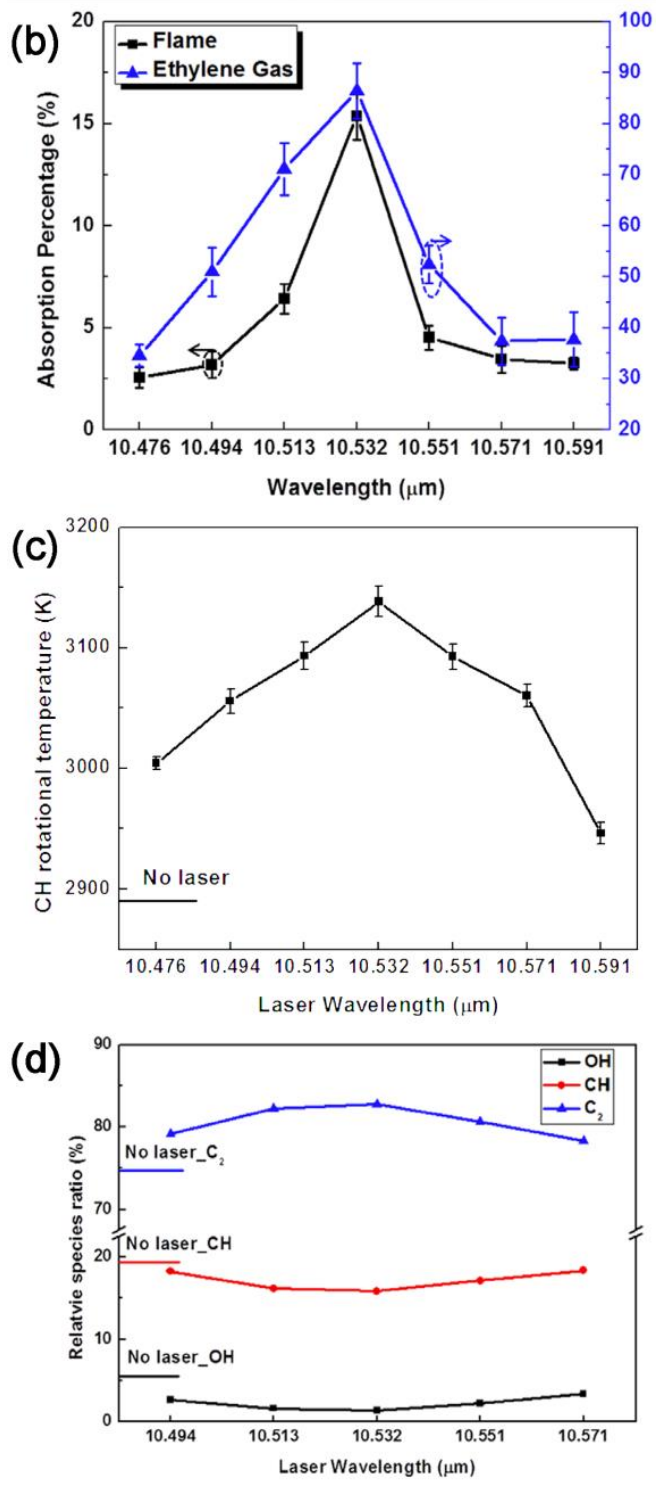

Figure 4 
a) No laser

d) $\lambda=10.532 \mu \mathrm{m}$

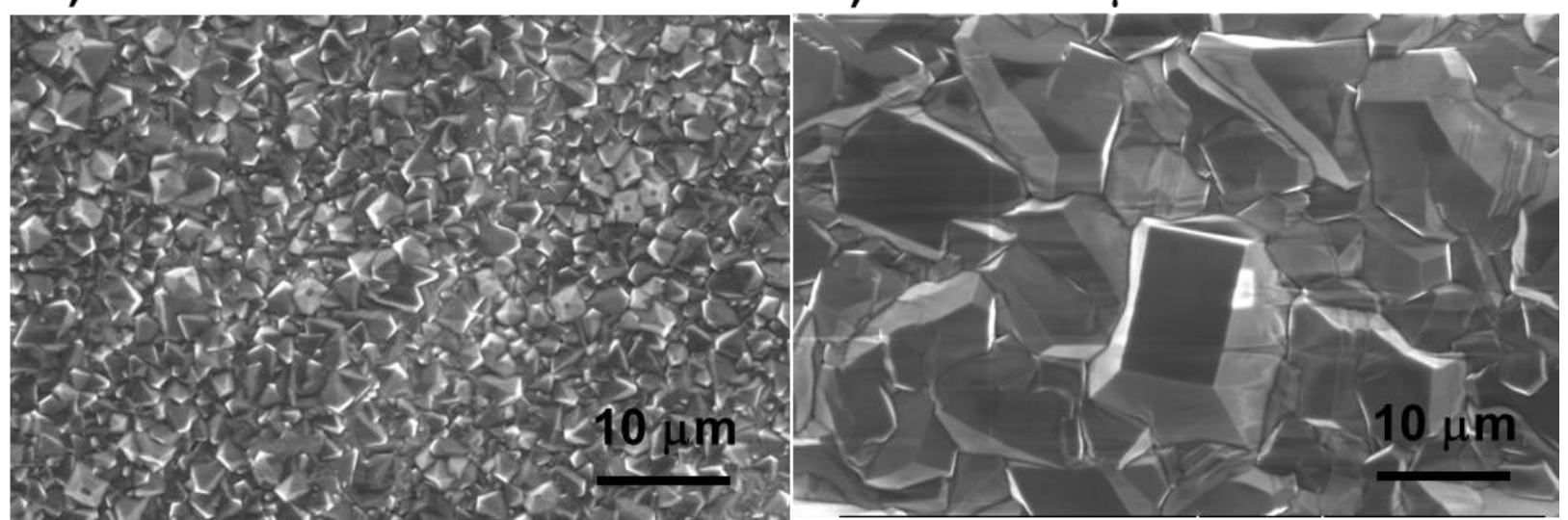

b) $\lambda=10.494 \mu \mathrm{m}$

e) $\lambda=10.551 \mu \mathrm{m}$

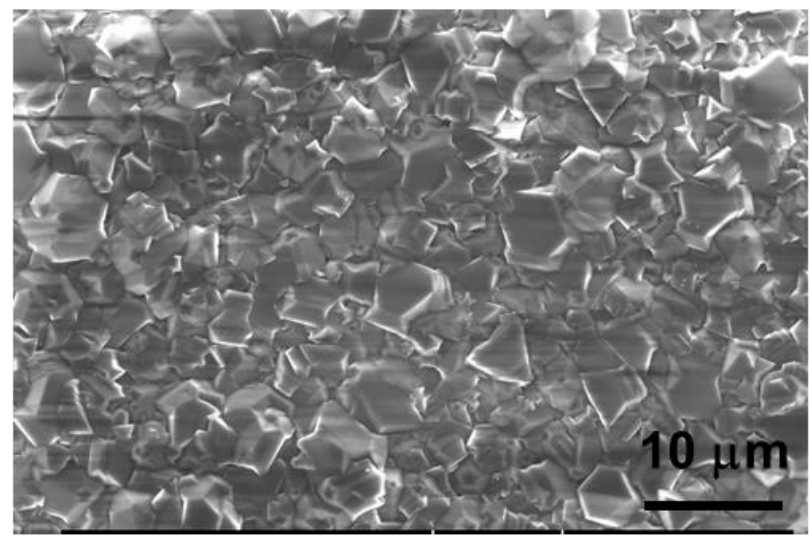

c) $\lambda=10.513 \mu \mathrm{m}$
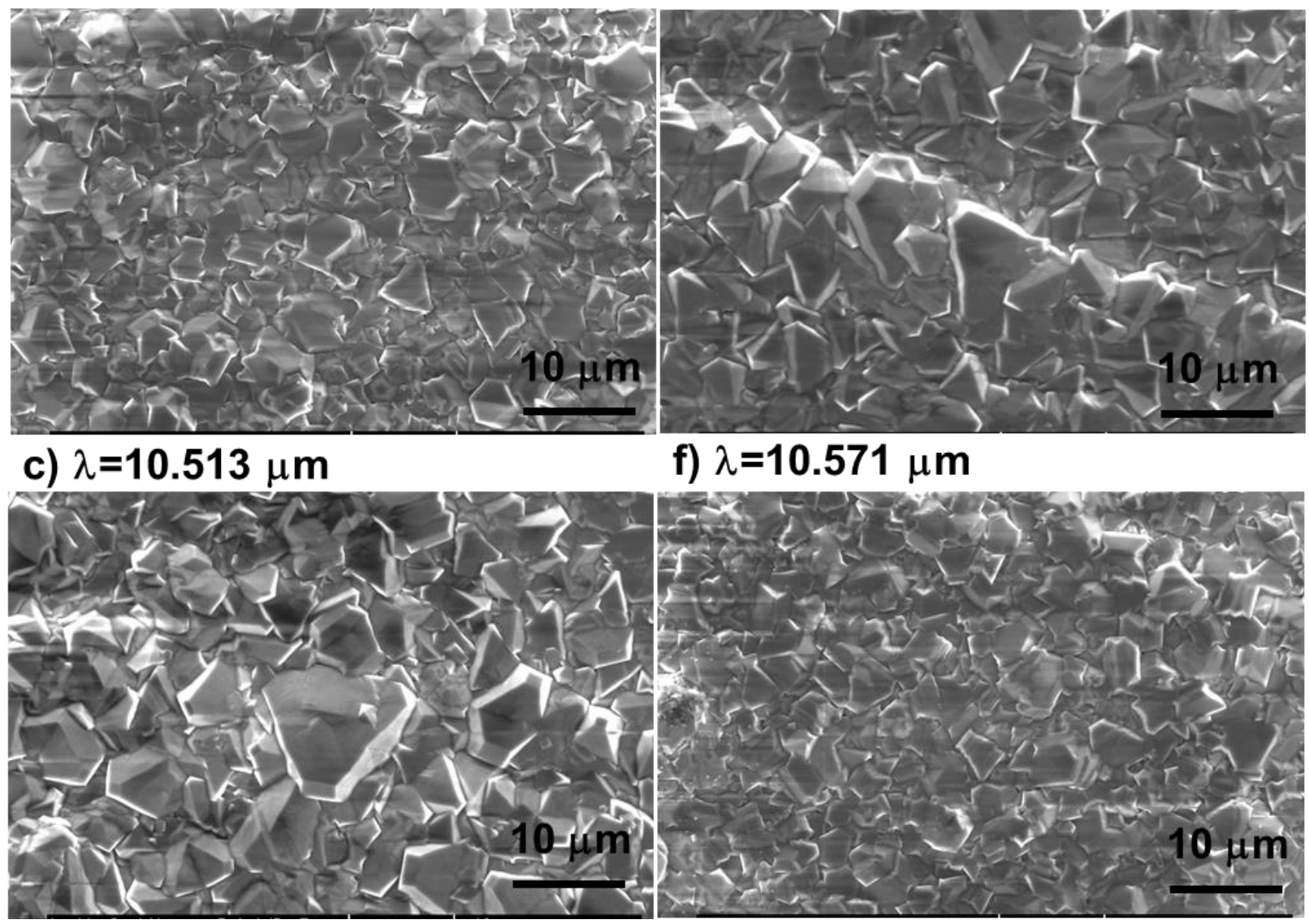

Figure 5 

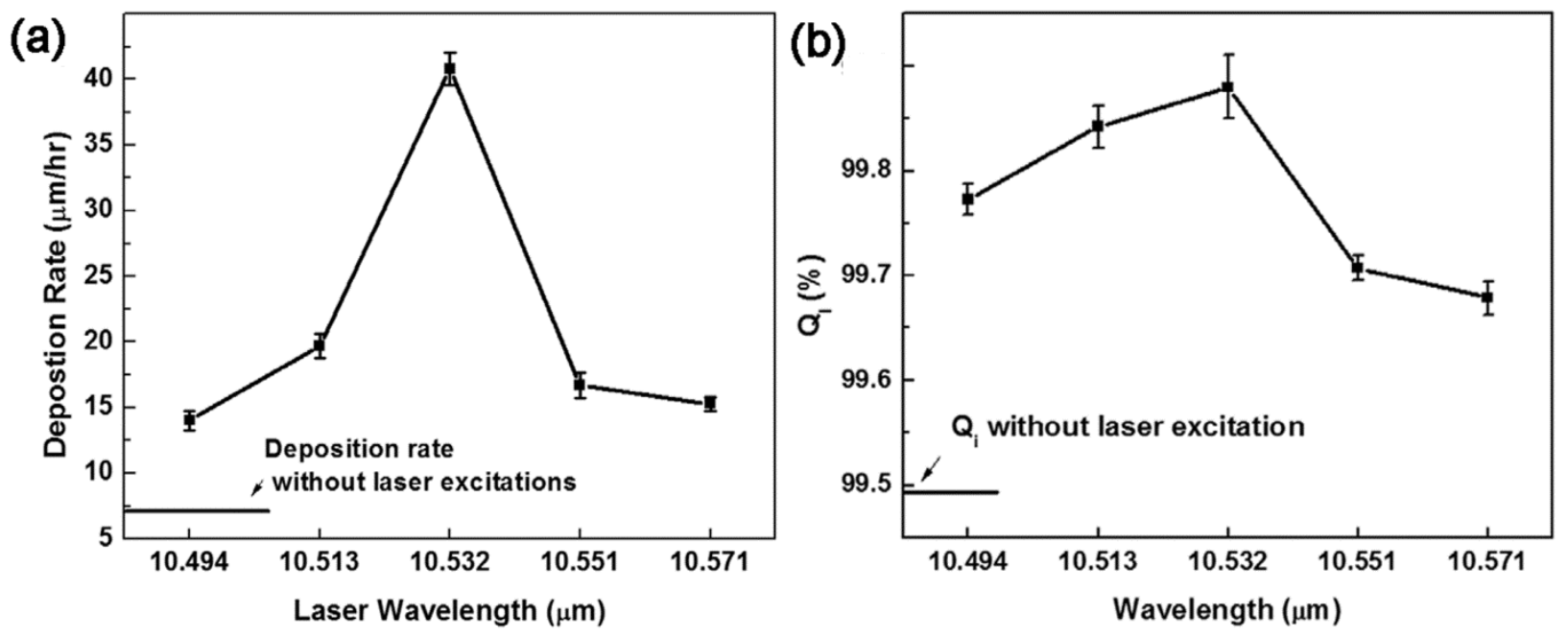

Figure 6 

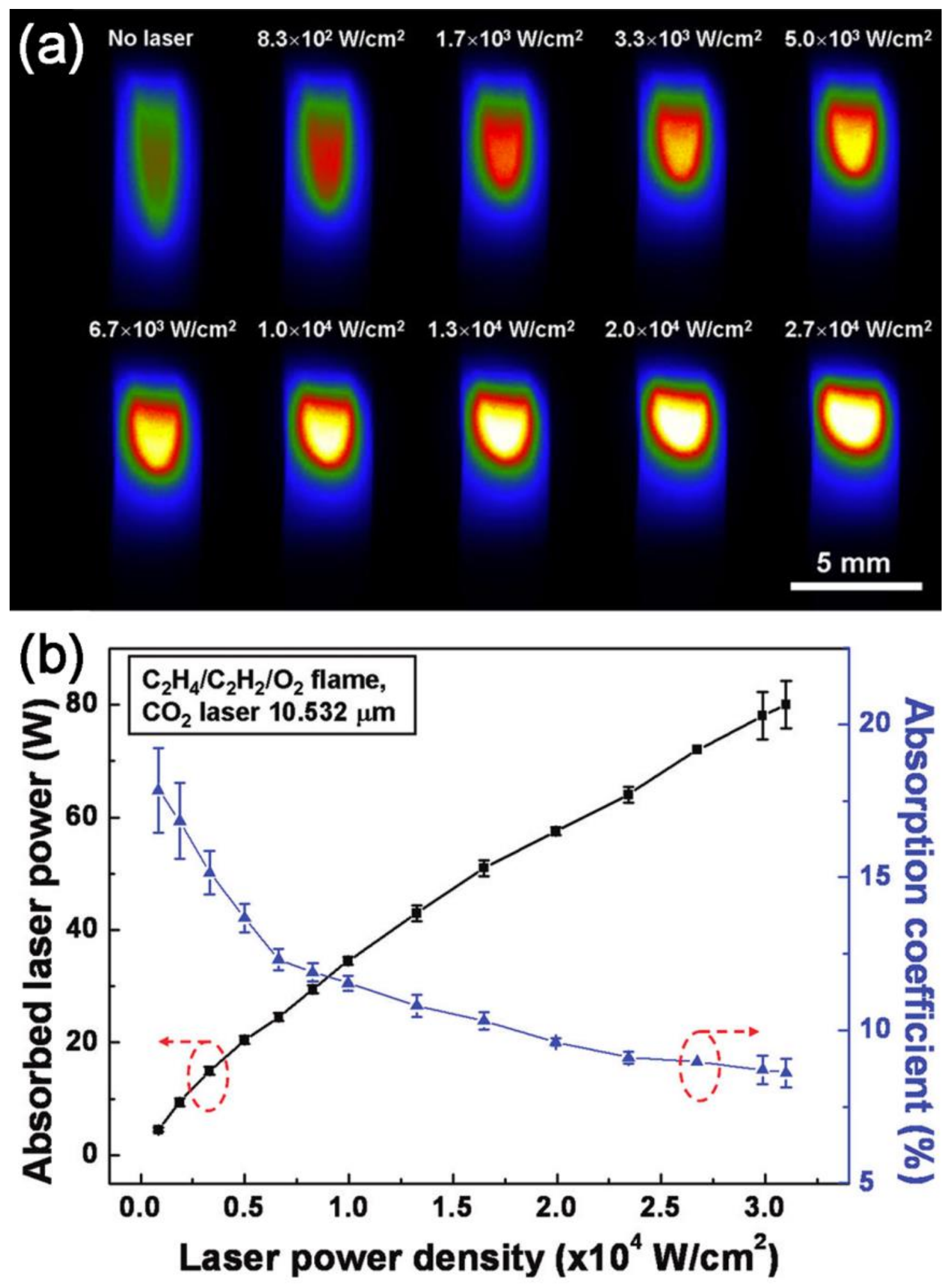

Figure 7 
(a) $0.0 \mathrm{~W} / \mathrm{cm}^{2}$

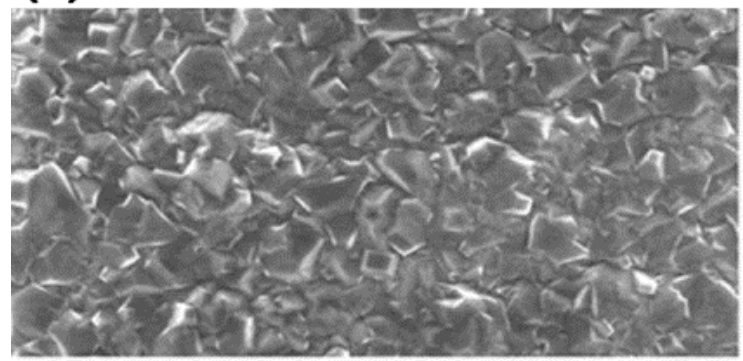

(b) $8.3 \times 10^{2} \mathrm{~W} / \mathrm{cm}^{2}$

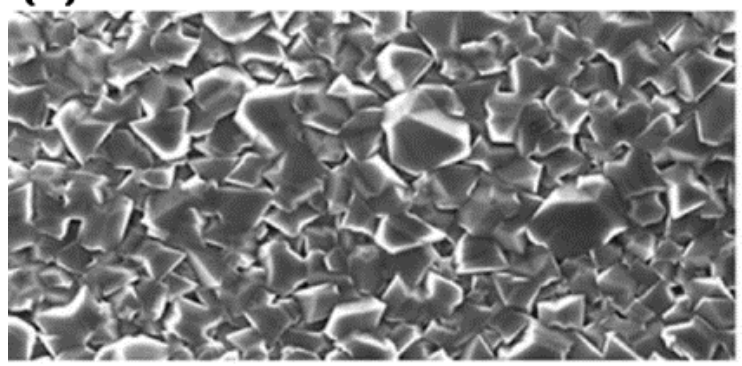

(c) $1.7 \times 10^{3} \mathrm{~W} / \mathrm{cm}^{2}$

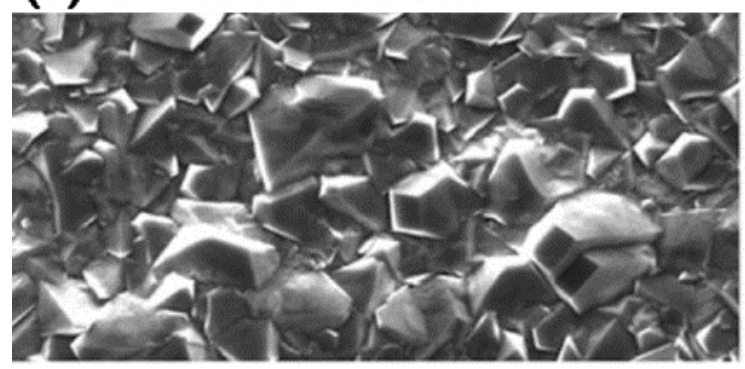

(d) $6.7 \times 10^{3} \mathrm{~W} / \mathrm{cm}^{2}$

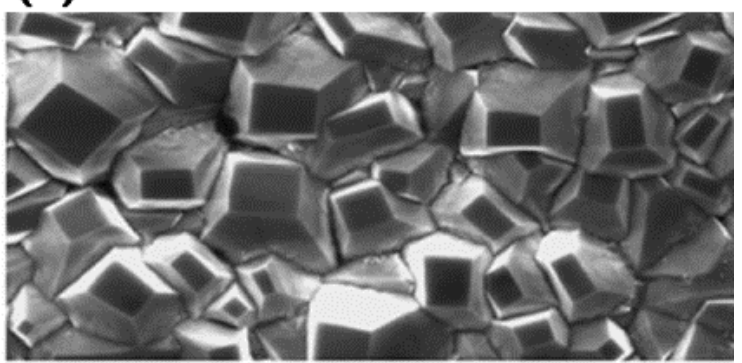

(e) $1.0 \times 10^{4} \mathrm{~W} / \mathrm{cm}^{2}$

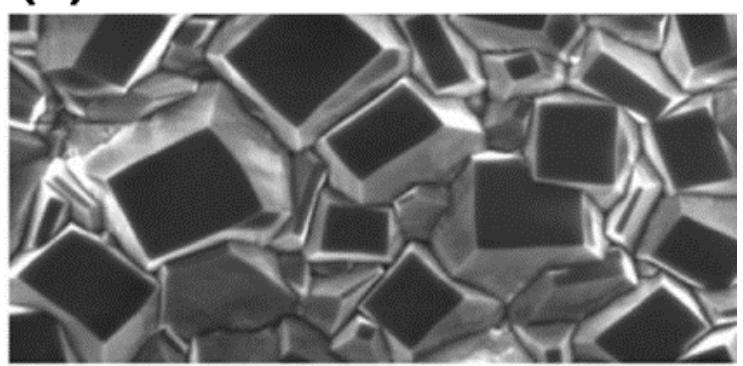

(f) $2.7 \times 10^{4} \mathrm{~W} / \mathrm{cm}^{2}$

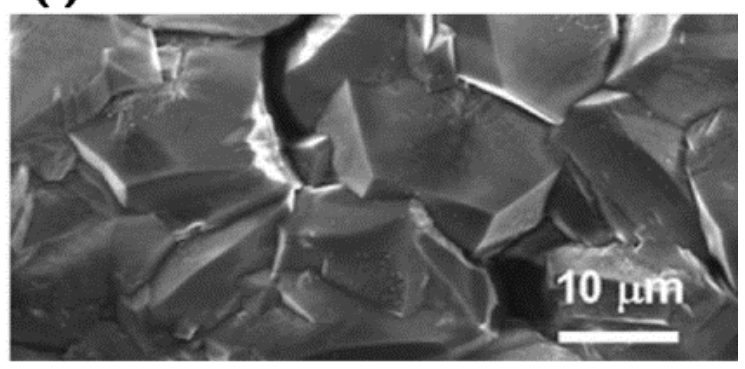

Figure 8 


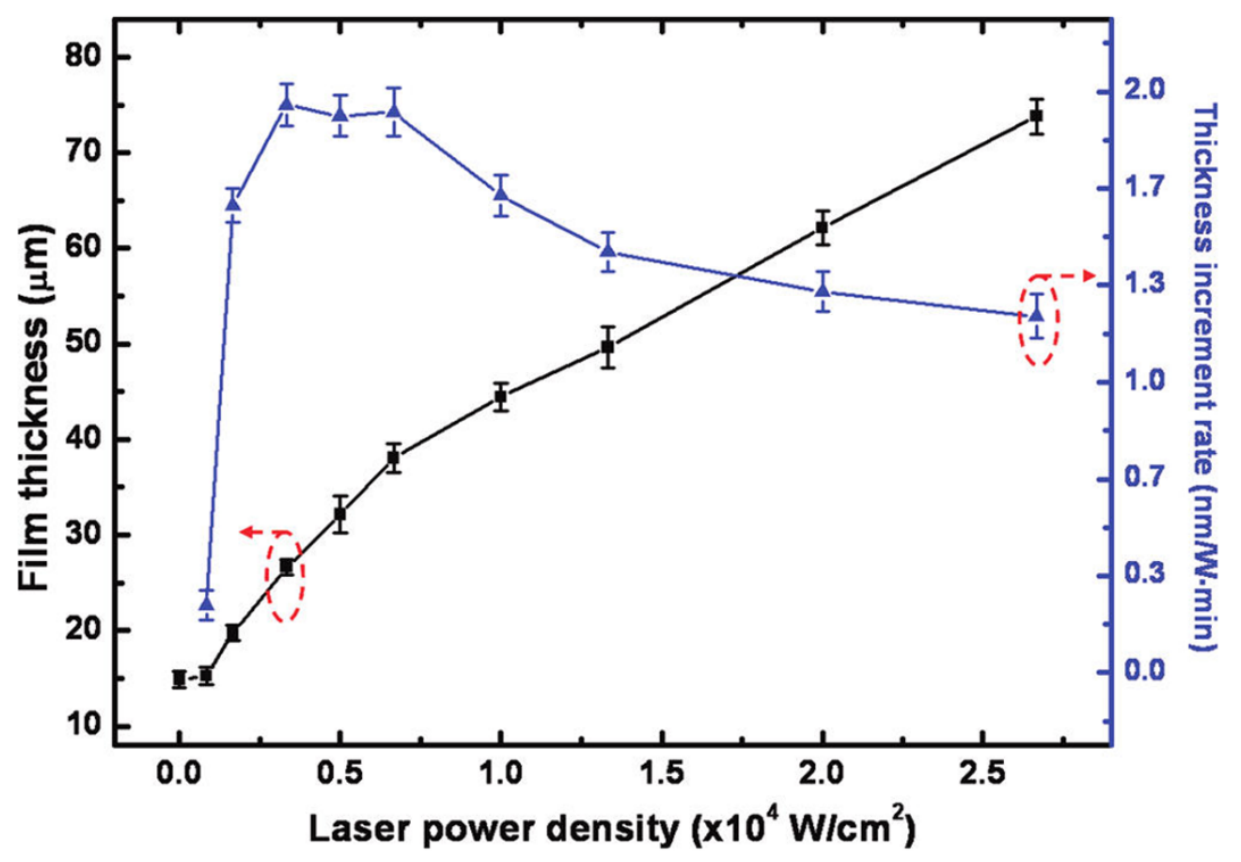

Figure 9 


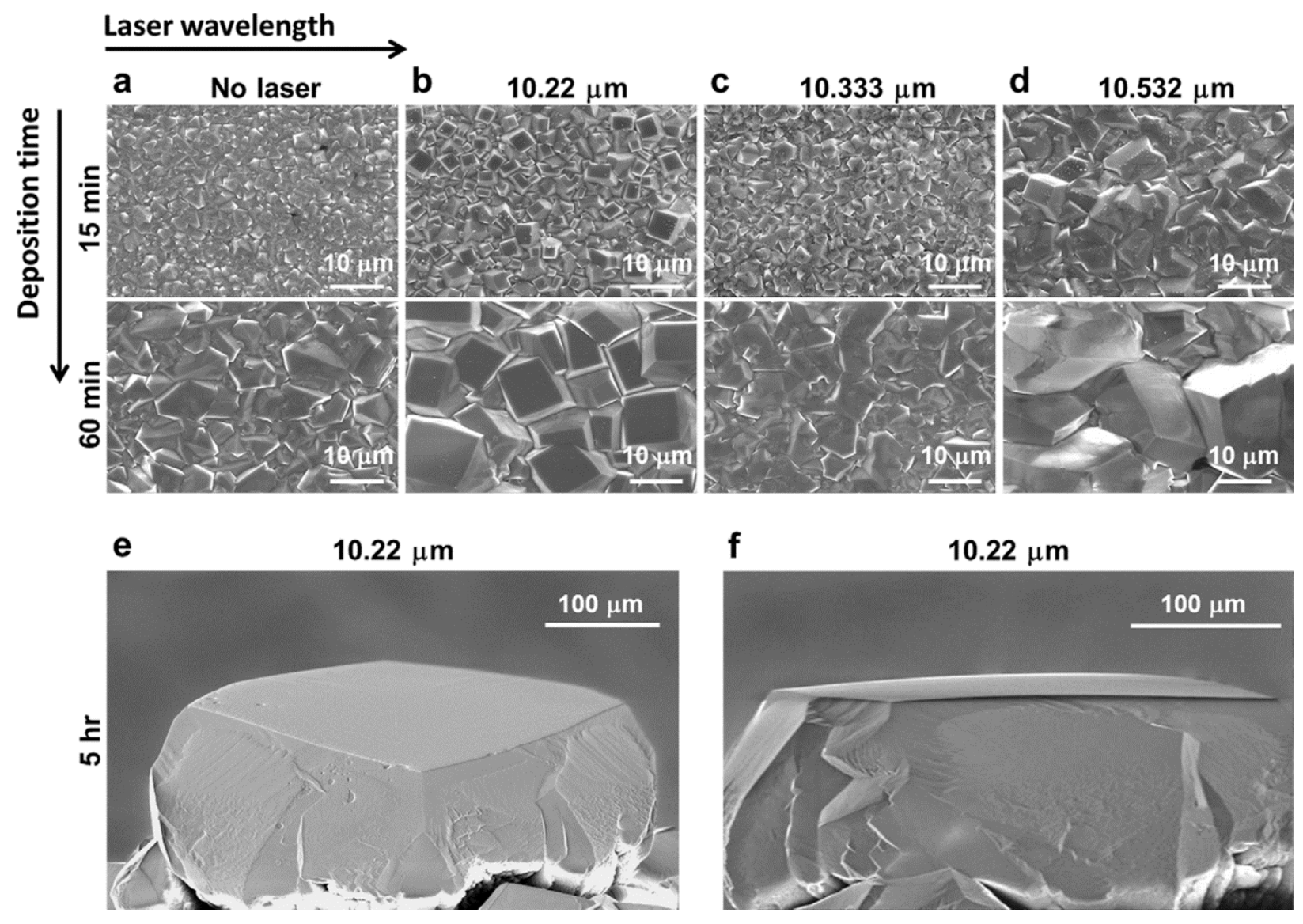

Figure 10 

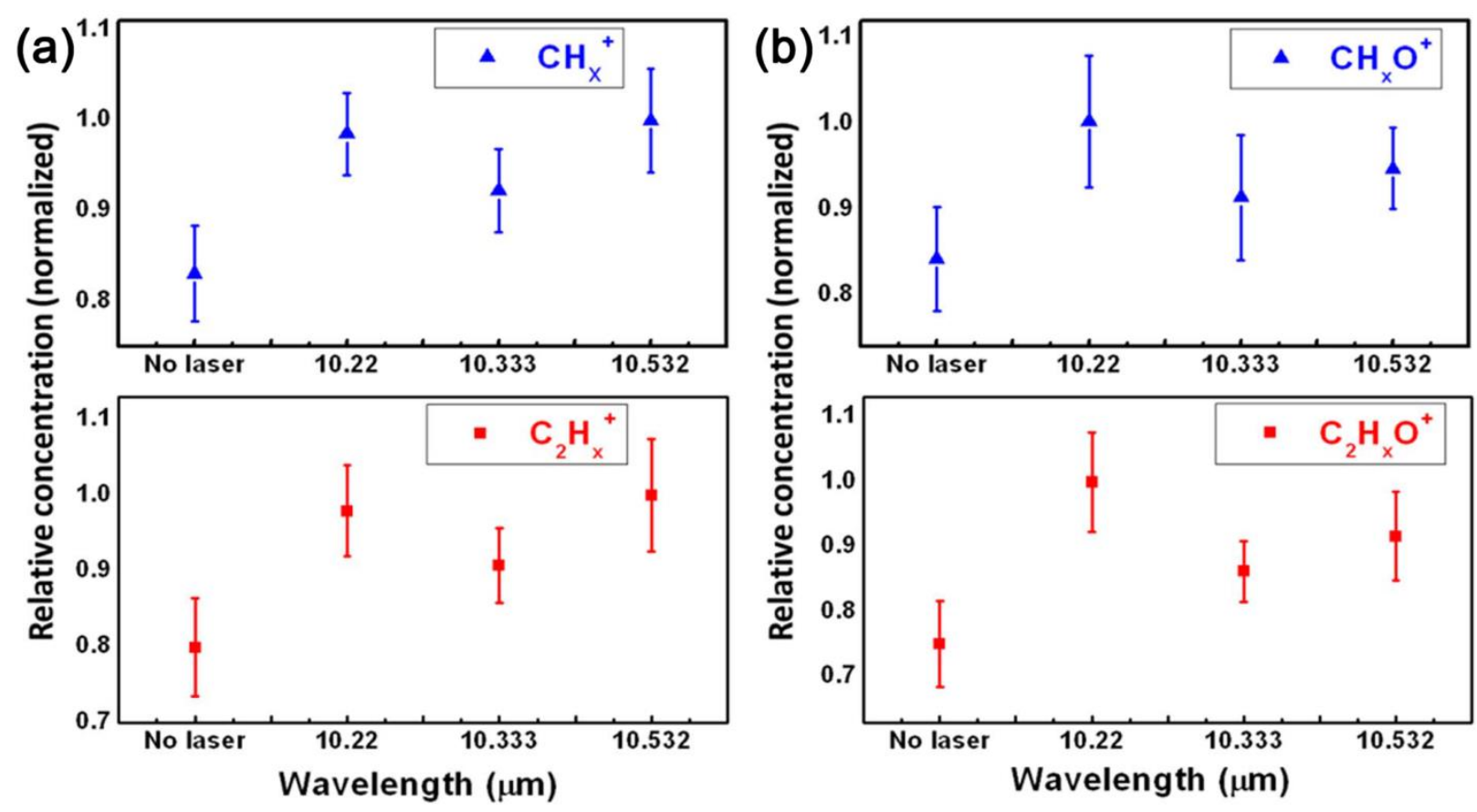

Figure 11 


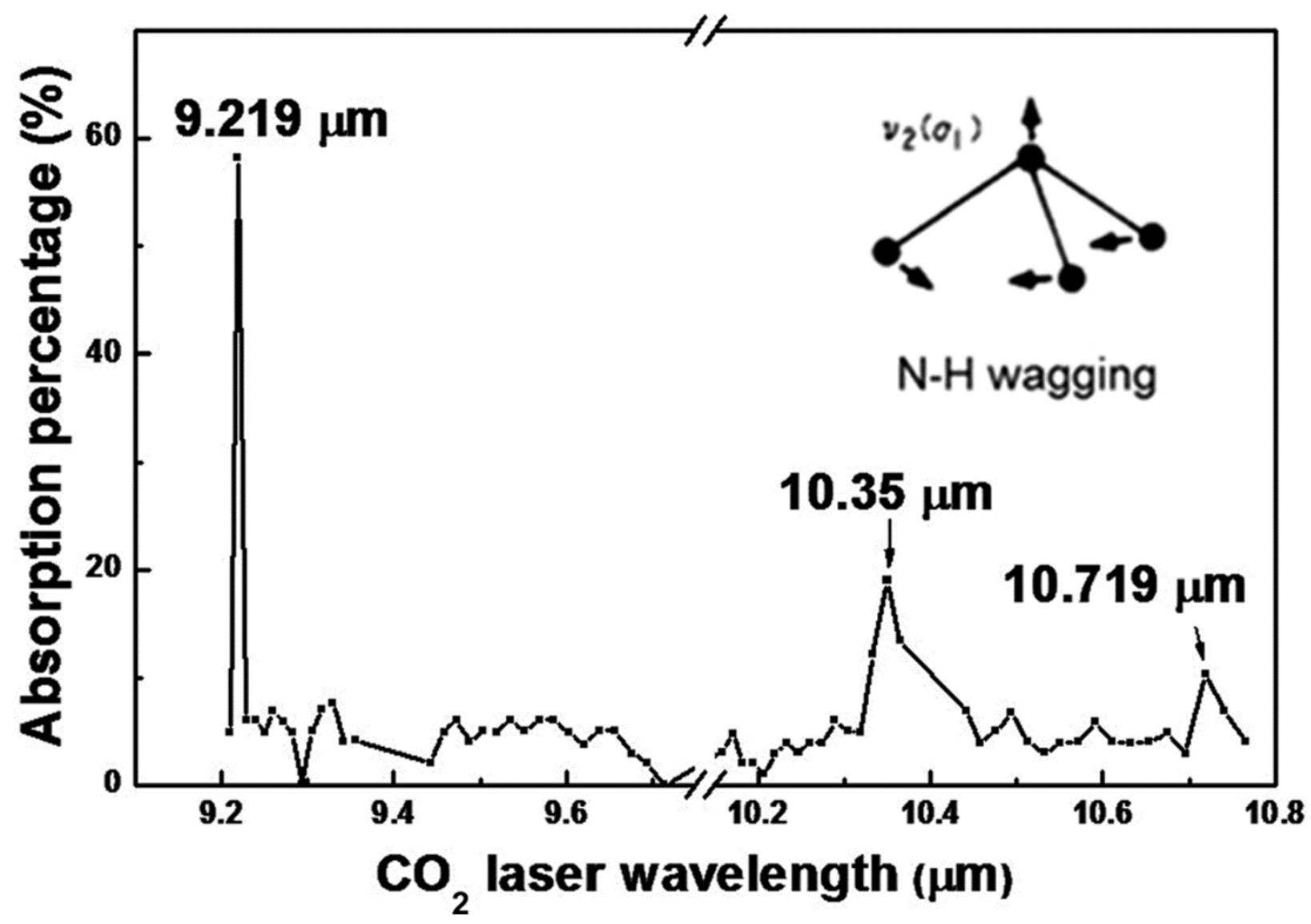

Figure 12 
(a) No $\mathrm{NH}_{3}$, no laser excitation

(b) No laser excitation

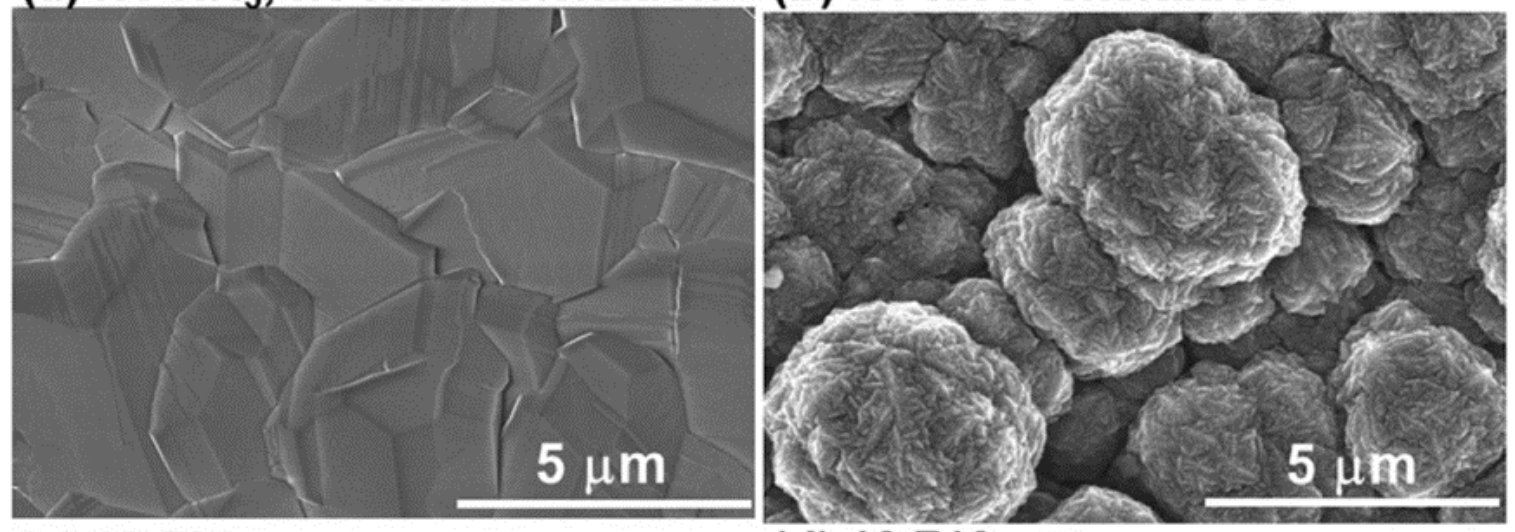

(c) $10.591 \mu \mathrm{m}$

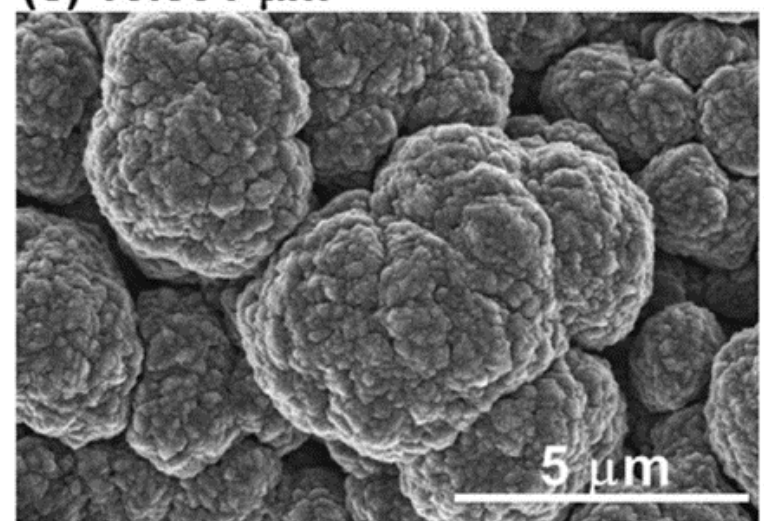

(e) $10.35 \mu \mathrm{m}$

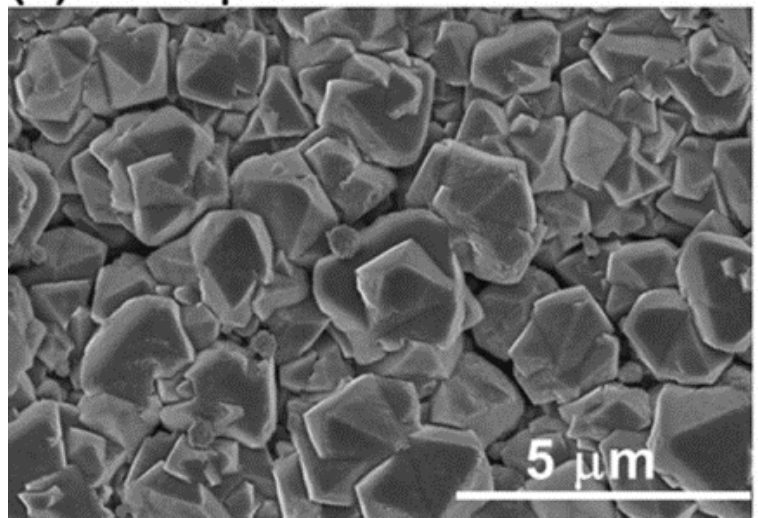

(d) $10.719 \mu \mathrm{m}$

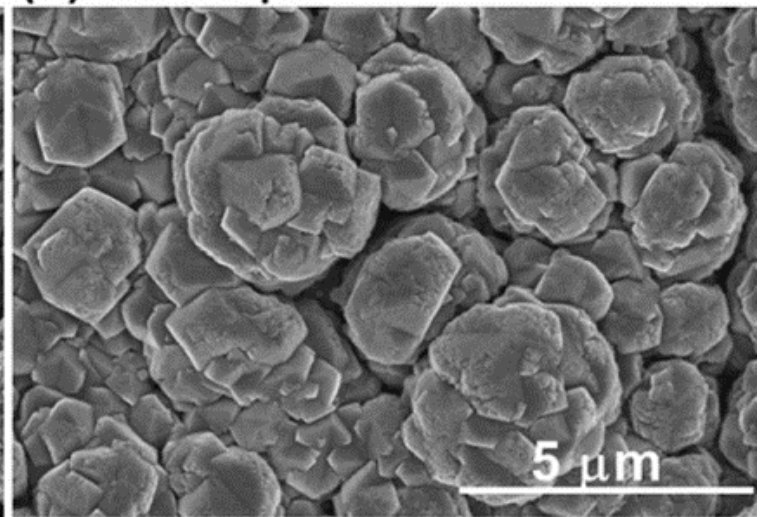

(f) $9.219 \mu \mathrm{m}$

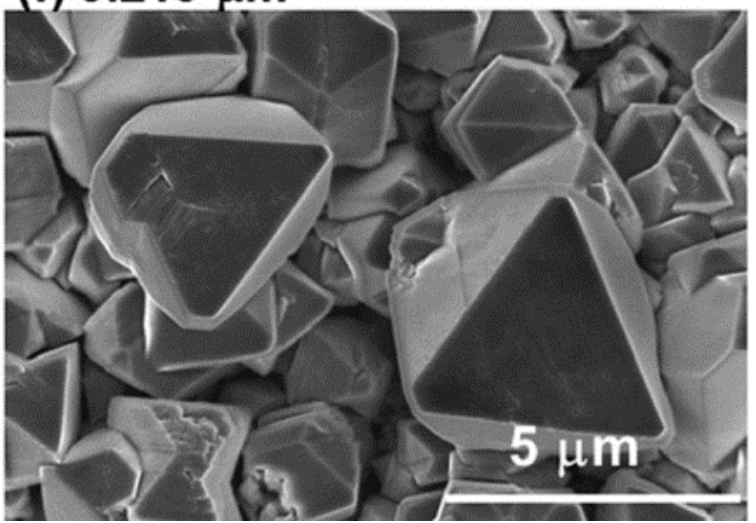

Figure 13 